\title{
Impediments to Advanced Technology Adoption for Canadian Manufacturers
}

\author{
by \\ John Baldwin* \\ and \\ Zhengxi Lin** \\ 11F0019MPE No. 173 \\ ISSN: 1200-5223 \\ ISBN: 0-662-30788-7 \\ No. 173
* Micro Economic Analysis Division 24th Floor, R.H. Coats Building Statistics Canada
Ottawa, K1A 0T6
(613) 951-8588
E-mail: baldjoh@statcan.ca
Fax: (613) 951-5403
** formerly of Statistics Canada and now with \\ Human Resources Development Canada
}

\section{August 2001}

The authors' names are listed alphabetically.

This paper represents the views of the authors and does not necessarily reflect the opinions of Statistics Canada. 


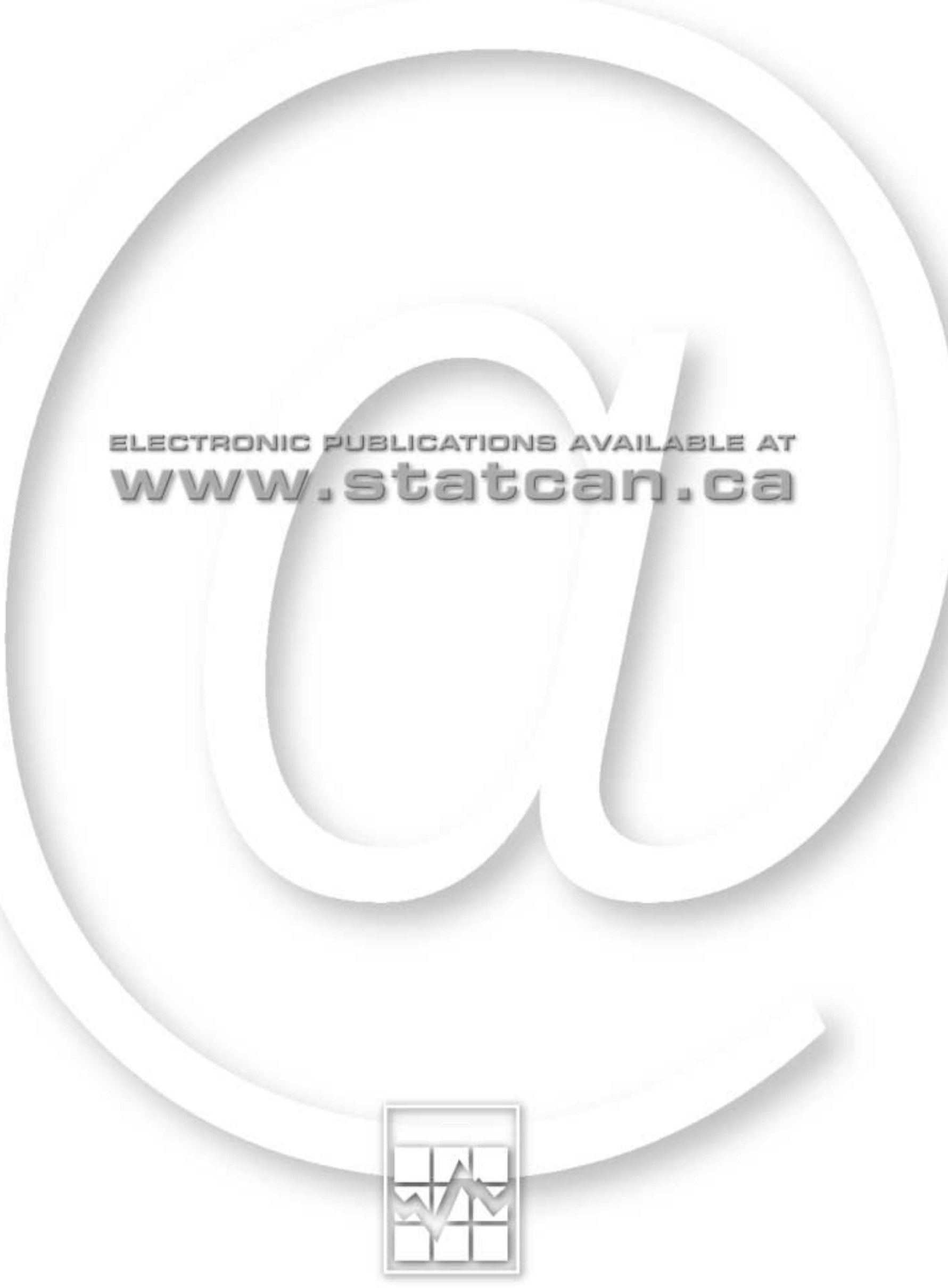




\section{Table of Contents}

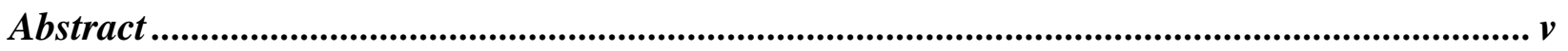

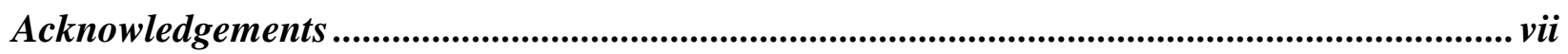

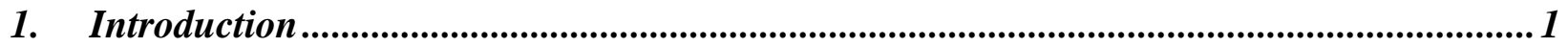

2. Advanced Technology Adoption: An Overview of Benefits and Impediments .................. 2

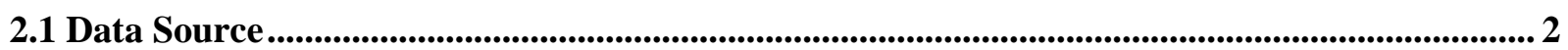

2.2 Benefits of Advanced Technology Adoption............................................................................... 4

2.3 Impediments to Advanced Technology Adoption ................................................................ 7

3. Determinants of Impediments to Advanced Technology Adoption ....................................... 11

3.1 Alternative Measures of Technologic and Innovative Activity..................................................... 11

3.2 Plant Characteristics....................................................................................................................................... 12

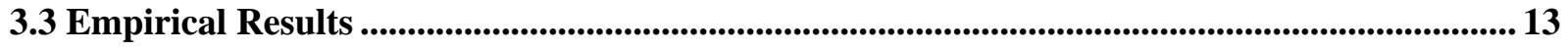

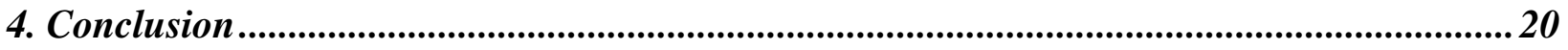

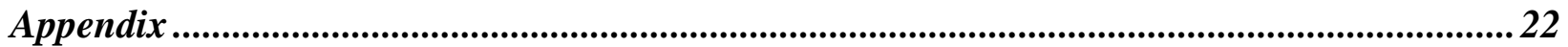

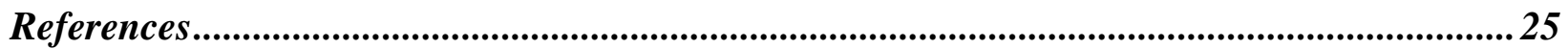




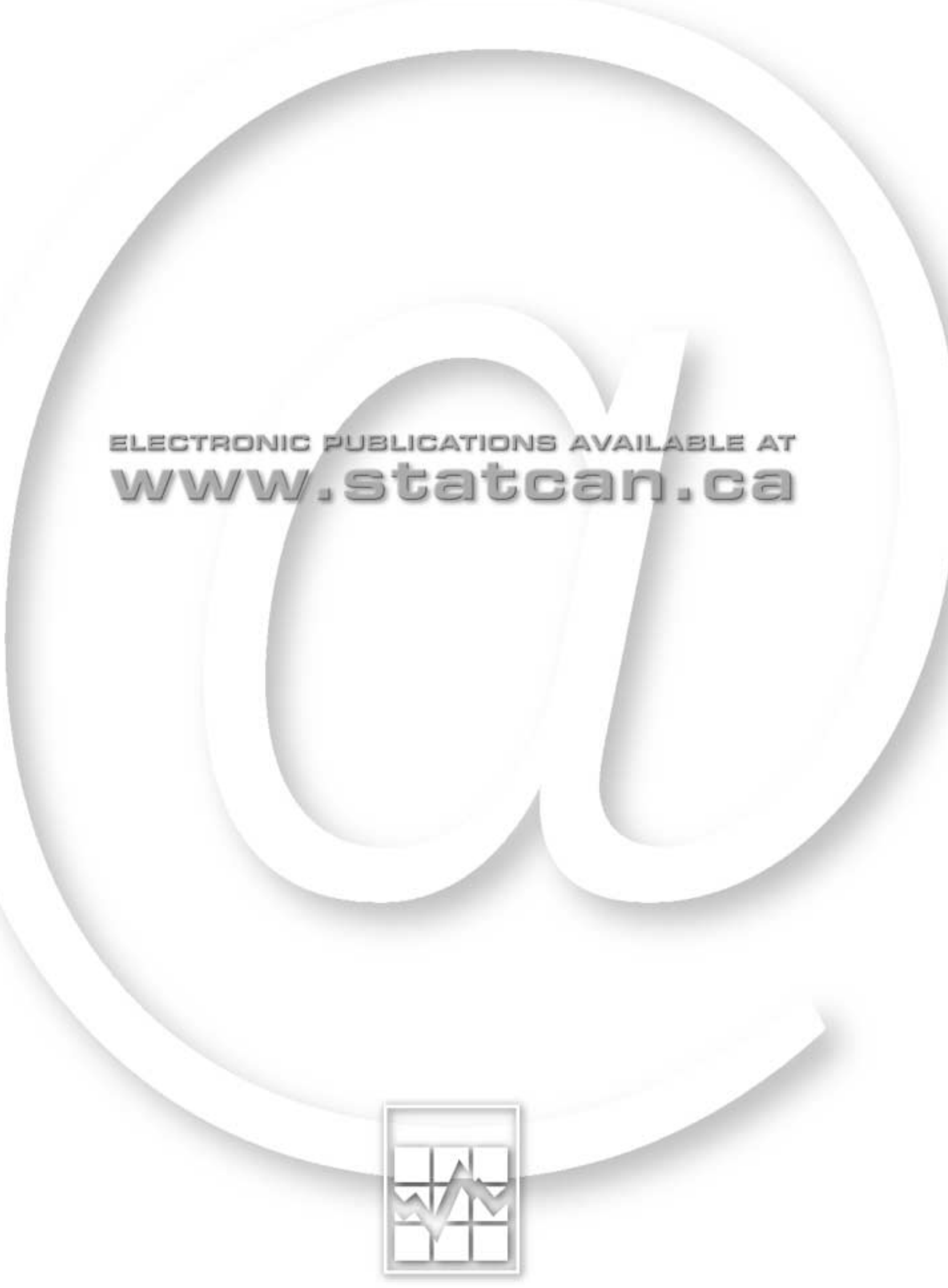




\begin{abstract}
Using survey data, this paper investigates problems that firms in the Canadian manufacturing sector face in their decision to adopt advanced technology. The data show that while the use of advanced technology is relatively important (users account for over $80 \%$ of all shipments), it is not widespread among firms (users represent only about one-third of all establishments). One explanation lies in the fact that while advanced technologies provide a wide range of benefits, firms also face a series of problems that impede them from adopting advanced technology. These impediments fall into five groups: cost-related, institution-related, labour-related, organizationrelated, and information-related.

While it might be expected that impediments would be higher for non-users than users of technologies, the opposite occurs. We posit that the reason for this is that innovation involves a learning process. Innovators and technology users face problems that they have to solve and the more innovative firms have greater problems. We test this by examining the factors that are related to whether a firm reports that it faced impediments. Our multivariate analysis reveals that impediments are reported more frequently among technology users than non-users; and more frequently among innovating firms than non-innovating ones. We conclude that the information on impediments in technology and other related surveys (innovation) should not be interpreted as impenetrable barriers that prevent technology adoption. Rather, these surveys indicate areas where successful firms face and solve problems.
\end{abstract}

Keywords: manufacturing, advanced technology adoption, benefits, costs, impediments JEL: L60, O33 


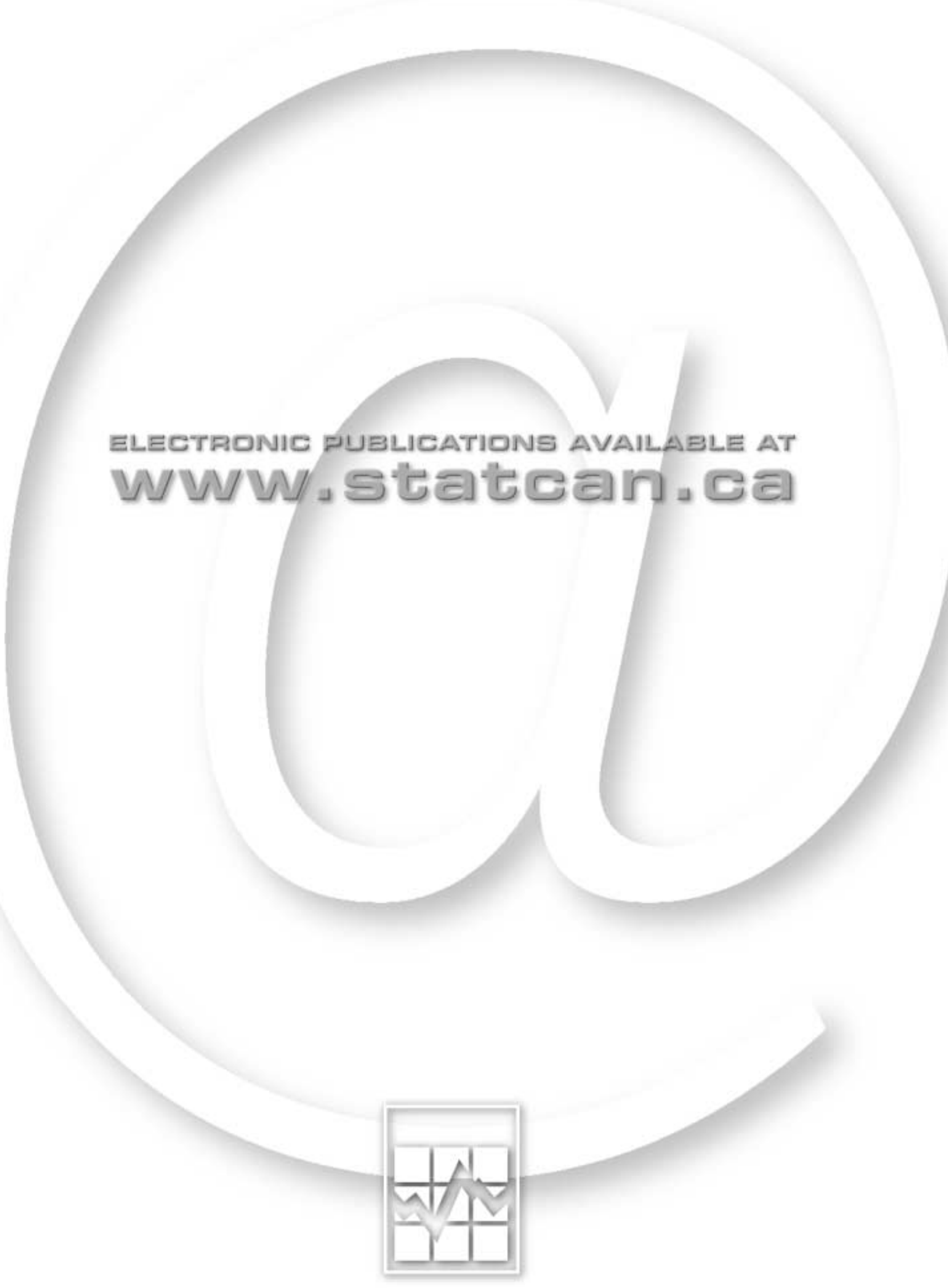




\section{Acknowledgements}

We would like to thank Bob Gibson and David Sabourin for their assistance with the data. An earlier version was presented at the 1999 Statistics Canada Economic Conference. We would also like to thank our discussant, David Steward-Patterson, and the conference participants for helpful comments and suggestions. A shortened version will be published in the journal Research Policy. 


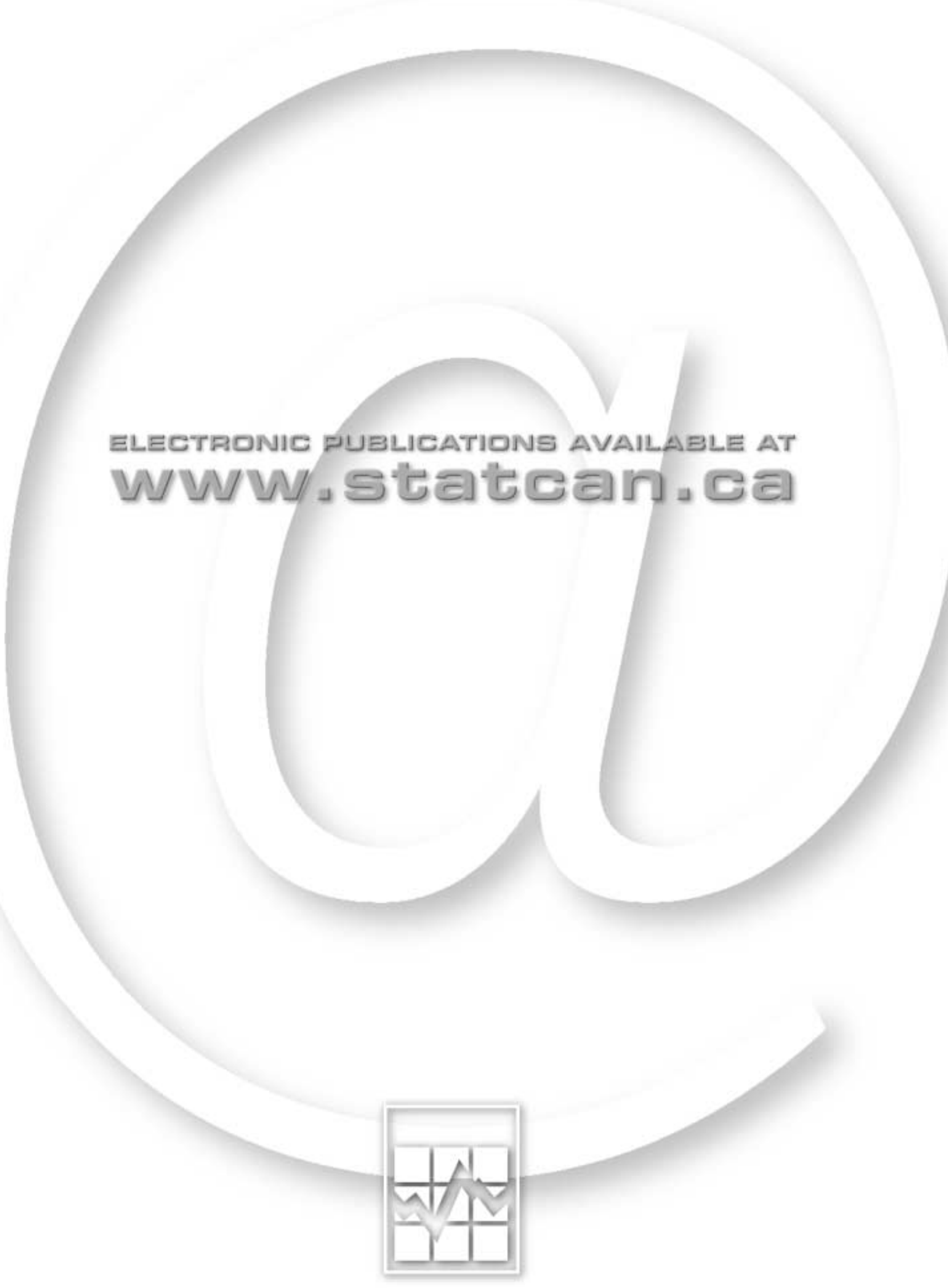




\section{Introduction}

Despite the fact that adoption of advanced technologies is closely related to productivity gains and other measures of firm performance (Baldwin, Diverty and Sabourin, 1995; Beaumont and Schroder, 1997; Papaconstantinou et al. 1996; Tracey, Vonderrembse and Lim, 1999), only about one-third of Canadian establishments used at least one advanced technology in their production process in 1993 (Baldwin and Sabourin, 1995). This raises the issue as to why some Canadian firms use advanced technologies extensively but others do not adopt them at all.

The decision to adopt advanced technologies ultimately rests with the benefits the technology provides and the costs associated with its adoption. In the 1993 Canadian Survey of Innovation and Advanced Technology, advanced technology users identified a wide range of benefits such as improvements in productivity, product quality and working conditions; reductions in production costs associated with such factors as lower labour requirements and inventory; reduced material and energy consumption; increased equipment utilization and reduced product rejection (Baldwin, Sabourin and Rafiquzzaman, 1996). At the same time, they also reported a host of costs associated with technology acquisition, e.g., education and training, time and cost to develop required software, and increased maintenance expenses. In addition to these costs, all firms reported a series of other impediments to their technology adoption. These include institution-related problems associated with tax regimes, and government regulations and standards; labour-related problems such as shortage of skills, training difficulties, and labour contracts; organizational or strategic problems associated with difficulties in introducing important changes to the organization, management attitude, and worker resistance; informationrelated problems such as lack of scientific and technical information, technological services, and technical support from vendors. Similar lists of impediments have been used to investigate barriers to innovation (Arundel, 1997).

This paper investigates the importance of impediments to the technology adoption process. We ask whether there is evidence that non-users of technology find that the impediments to adoption are greater than do technology users and whether there are particular areas where the impediments are greatest. Section 2 discusses the survey data used and provides an overview of the benefits and impediments outlined by plant managers. Section 3 examines the factors that are related to a plant reporting that it faces an impediment. The section focuses primarily on whether non-users of technology are more likely to report an impediment. We find that technology users are more likely, not less likely, to report many types of impediments. We conclude that barriers to technology adoption, at least as measured in technology surveys, should not be interpreted to be impenetrable barriers that prevent technology adoption. Rather, these surveys indicate areas where successful firms face and solve problems. 


\section{Advanced Technology Adoption: An Overview of Benefits and Impediments}

Since the technology adoption decision is closely related to the net benefits that are perceived to flow from the implementation of new equipment, this section outlines the benefits of advanced technology adoption in the Canadian manufacturing sector, and the extent to which firms face various impediments. We begin with a brief introduction of the data used in the analysis.

\subsection{Data Source}

The data used for this analysis are extracted from the 1993 Survey of Innovation and Advanced Technology (SIAT) of Statistics Canada. Stratified by size, industry and province, the 1993 SIAT sample is randomly drawn from a frame of all establishments in the Canadian manufacturing sector, which is maintained in the Business Register Division of Statistics Canada. There are eight sections to the survey questionnaire. Three sections of the survey examine the incidence of advanced technology use at the plant level, the benefits derived therefrom, and the impediments that plants reported as delaying technology adoption. The survey also explores the innovation activity of the firm owning the plant-incidence of innovation, existence of research and development units, and the characteristics of the firm's competitive environment. These data provide us with measures of impediments to technology use and measures of the technological and innovative activity of establishments and their owning enterprises. In addition, the survey provides us with certain general characteristics such as ownership, degree of competition, and extent of employee unionization. More details on the survey can be found in Baldwin and Sabourin (1995), and Baldwin, Sabourin and Rafiquzzaman (1996).

Data from the SIAT survey are combined with data drawn from the Census of Manufactures of Statistics Canada on various characteristics of each of the plants in the survey-size, age, nationality (domestic- or foreign-controlled), and growth over the decade prior to the survey. These and other characteristics are used in a multivariate analysis to determine the factors that are related to whether a firm indicated that it faced different impediments to the acquisition and adoption of advanced technology.

The survey collects information on 22 detailed advanced manufacturing technologies. ${ }^{1}$ For this analysis, these categories are classified into six groups according to their specific function in the production process-design and engineering, fabrication and assembly, automated material handling, inspection and communications, manufacturing information systems, and integration and control. Table 1 itemizes these technologies and the functional group into which they fall.

\footnotetext{
${ }^{1}$ Related surveys that focus only on technology have been done by the Australian Bureau of Statistics (1989) and the U.S. Bureau of the Census $(1989,1993)$.
} 
Table 1. Advanced Manufacturing Technologies

\begin{tabular}{|c|c|c|}
\hline Functional Group & Technology & Description \\
\hline $\begin{array}{l}\text { Design and } \\
\text { Engineering }\end{array}$ & $\begin{array}{l}\text { - } \quad \text { Computed-aided design/engineering } \\
\text { - } \quad \text { CAD output to control manufacturing } \\
\text { - } \quad \text { Digital representation of CAD output }\end{array}$ & $\begin{array}{l}\text { - Use of computers for drawing and designing parts or products (CAD/CAE) } \\
\text { - Use of CAD output for controlling manufacturing machines } \\
\text { - Use of digital representation of CAD output for controlling manufacturing machines }\end{array}$ \\
\hline $\begin{array}{l}\text { Fabrication and } \\
\text { Assembly }\end{array}$ & $\begin{array}{ll}\text { - } & \text { Flexible manufacturing cells/systems } \\
\text { - } & \text { Numerically controlled and computer } \\
\text { - } & \text { numerically controlled machines } \\
\text { - } & \text { Pick and place robots } \\
\text { - } & \text { Other robots }\end{array}$ & $\begin{array}{l}\text { - Machines with fully integrated material handling capabilities controlled by computers } \\
\text { or programmable controllers } \\
\text { - A single machine numerically/computer-numerically controlled with/without } \\
\text { automated material handling capabilities } \\
\text { - Laser technology used for welding, cutting, treating, scribing and marking } \\
\text { - A simple robot which transfers items from one place to another }\end{array}$ \\
\hline $\begin{array}{l}\text { Automated Material } \\
\text { Handling }\end{array}$ & $\begin{array}{l}\text { - } \quad \text { Automated storage/retrieval systems } \\
\text { - } \quad \text { Automated guided vehicle systems }\end{array}$ & $\begin{array}{l}\text { - Computer-controlled equipment for the automatic handling and storage of materials, } \\
\text { parts, sub-assemblies or finished products } \\
\text { - Vehicles equipped with automatic guidance devices }\end{array}$ \\
\hline $\begin{array}{l}\text { Inspection and } \\
\text { Communications }\end{array}$ & $\begin{array}{l}\text { - Automatic inspection equipment for } \\
\text { incoming materials } \\
\text { - } \quad \text { Automatic inspection equipment for } \\
\text { final products } \\
\text { - Local area network for technical data } \\
\text { - } \quad \text { Inter-company computer network } \\
\text { - } \quad \text { Programmable controllers } \\
\text { fomputers used for control in } \\
\text { factories }\end{array}$ & $\begin{array}{l}\text { - Automatic sensor-based equipment used for inspecting or testing incoming or in- } \\
\text { process materials } \\
\text { - Automatic sensor-based equipment used for inspecting/testing final products } \\
\text { - Use of local area network (LAN) to exchange technical data with design and } \\
\text { - } \text { Usineering departments } \\
\text { - Networks to exchange information between different points on the factory floor } \\
\text { - Control device that has programmable memory for storage of instruction } \\
\text { - Computers on the factory floor that may be dedicated to control, but which are } \\
\text { capable of being reprogrammed for other functions }\end{array}$ \\
\hline $\begin{array}{l}\text { Manufacturing } \\
\text { Information Systems }\end{array}$ & $\begin{array}{l}\text { - } \\
\text { - } \\
\text { Manuferials requirement planning } \\
\text { Maning resource planning }\end{array}$ & $\begin{array}{l}\text { - Computer-based production management and scheduling system to control order } \\
\text { quantities, inventory and finished products } \\
\text { - Computer-based production management of machine loading and production } \\
\text { scheduling, as well as inventory control and material handling }\end{array}$ \\
\hline $\begin{array}{l}\text { Integration and } \\
\text { Control }\end{array}$ & $\begin{array}{l}\text { - } \quad \text { Computer integrated manufacturing } \\
\text { - Supervisory control and data } \\
\text { - } \quad \text { Artificitial intelligence/expert systems }\end{array}$ & $\begin{array}{l}\text { - All manufacturing processes are integrated and controlled by a central computer } \\
\text { - On line, computer-based monitoring and control of process and plant variables at a } \\
\text { central site } \\
\text { - A machine performing tasks normally attributed to human intelligence/the } \\
\text { computerization of knowledge of experts in narrowly defined fields, e.g., fault finding }\end{array}$ \\
\hline
\end{tabular}


Table 2. Advanced Technology Adoption in the Canadian Manufacturing Sector, 1993

\begin{tabular}{l|c|c|c|c}
\hline \multirow{2}{*}{} & \multicolumn{4}{|c}{ Number of Technologies in Use } \\
\cline { 2 - 5 } & 0 & 1 to 4 & 5 to 9 & $10+$ \\
\hline \% of Shipments & 18.9 & 22.3 & 26.7 & 32.1 \\
\hline
\end{tabular}

Source: Baldwin and Sabourin (1995).

Technology-using plants tend to be large, though not numerous. Establishments that used at least one advanced technology accounted for over $81 \%$ of all Canadian manufacturing shipments in 1993 (Table 2). ${ }^{2}$ However, the adoption of advanced technologies is not extensive. Only a little over one-third of establishments used at least one advanced technology.

What is it then that leads some firms to use advanced technologies but others to not adopt them at all? The decision to adopt advanced technologies ultimately rests on the benefits that the technology provides and the costs associated with its adoption. The latter depend upon the impediments that firms face. The next two sub-sections outline the benefits and impediments associated with technology adoption.

\subsection{Benefits of Advanced Technology Adoption}

The benefits of technology use are far ranging-from increasing productivity, to improving flexibility, to producing higher quality products, to reducing production costs (Beaumont and Schroder, 1997; Rischel and Burns, 1997; Small, 1998).

Improvements in productivity occur when the same output can be produced with fewer inputs. This leads to a reduction in production costs. Production costs can also be reduced when lower cost inputs can be substituted for higher cost inputs, when lower skilled labour can be substituted for higher skilled labour. Flexibility is a benefit when product line diversity can be extended by new technologies. Product quality improvements result from lower scrappage rates or from more reliable products, i.e., computer power sources that have lower failure rates.

The benefits and effects associated with advanced technology adoption reported by managers in technology-using plants are itemized in Table 3 . Since benefits are likely to be technology specific and the functional groups adopted correspond to different stages of the production process, the benefits are reported for of each of the four different functional groups described above-design and engineering (DE), fabrication and assembly (FA), automatic material handling $(\mathrm{AMH})$, and inspection and communications (IC). ${ }^{3}$ Columns 1 to 4 are weighted by shipments; Columns 5 to 8 by establishments. ${ }^{4}$ It should be noted, of course, that the functional groups are not used independently of one another. But by comparing how the percentage of

\footnotetext{
${ }^{2}$ An additional 3\% of shipments were accounted for by establishments that planned to use at least one advanced technology within the next two years.

${ }^{3}$ The other two functional groups of technologies (manufacturing information systems, and integration and control) are relatively uncommon and not as frequently used. Their results are hence not reported.

4 Shipment-weighted percentages indicate the proportion of shipments from plants that used the technology. Establishment-weighted percentages present the fraction of establishments using the technology.
} 
plants (weighted or unweighted by shipments) reporting a specific benefit differs across functional group categories, we can investigate whether the most important categories varies by functional group. Generally, they do not.

An improvement in overall productivity (sometimes referred to as total factor productivity) is the most frequently reported benefit associated with advanced technology adoption. Over half of design and engineering, fabrication and assembly, and automatic material handling technology users reported an improvement in productivity. The dominance of this benefit is even more evident when the results are weighted by shipments. Design and engineering, fabrication and assembly, and automatic material handling technology users that registered an improvement in productivity accounted for $70 \%$ to $77 \%$ of shipments. Productivity improvement is also the most important benefit category for inspection and communication technology users, but here it shares the lead with improvements in product quality.

Overall productivity improvements can be achieved through a variety of means, e.g., a reduction in labour usage, raw material or energy consumption, and better equipment utilization. To various degrees, advanced technology users identify benefits in all of these areas. But the dominant category here is a reduction in labour requirements. Labour costs are not, however, reduced by substituting unskilled for skilled labour. In general, a larger percentage of firms indicates that skill levels increased rather than decreased. Generally, the second most important cause of productivity enhancement results from increases in equipment utilization-especially in large plants using fabrication and assembly and automated material handling technologies. In all cases, the adoption of advanced technologies led to greater, not less, capital investment. Thus the benefits of advanced technology use are accompanied by greater costs-both because of the need for more skilled labour and increases in capital investment.

The second most important benefit resulting from the adoption of advanced technologies is an improvement in product quality. One-third to slightly more than half of users felt that their product quality had improved; the share of total user shipments accounted for by establishments reporting such a benefit ranged from a low of $47 \%$ for design and engineering technology users to a high of $65 \%$ for technology users in the fabrication and assembly area. Much of this quality improvement is associated with lower scrappage rates. The percentage of establishments indicating that they had lower product rejection rates as a result of the introduction of advanced technologies is almost as high as those indicating that product quality had improved-especially so for users of advanced technologies in fabrication and assembly.

Advanced technology users also report that improved product flexibility was a benefit thereby confirming predictions that new advanced technologies would have a dramatic effect in this area (Young, Francis and Young, 1993; Spina et al., 1996). Finally, a good percentage of firms report that working conditions had improved as a result of advanced technology use. In summary, advanced technology users report an impressive list of benefits, with productivity and quality improvements being the most important. 
Table 3. Benefits and Effects of Advanced Technology Adoption

\begin{tabular}{|c|c|c|c|c|c|c|c|c|}
\hline \multirow[b]{2}{*}{ Benefit/Effect } & \multicolumn{4}{|c|}{$\%$ of Shipments } & \multicolumn{4}{|c|}{$\%$ of Establishments } \\
\hline & $\begin{array}{c}\text { Design } \\
\text { and } \\
\text { engineering } \\
\text { (1) }\end{array}$ & $\begin{array}{l}\text { Fabrication } \\
\text { and } \\
\text { assembly } \\
\text { (2) }\end{array}$ & $\begin{array}{c}\text { Automatic } \\
\text { material } \\
\text { handling } \\
\text { (3) }\end{array}$ & $\begin{array}{c}\text { Inspection } \\
\text { and } \\
\text { communications } \\
\text { (4) }\end{array}$ & $\begin{array}{c}\text { Design } \\
\text { and } \\
\text { engineering } \\
(5)\end{array}$ & $\begin{array}{l}\text { Fabrication } \\
\text { and } \\
\text { assembly } \\
\text { (6) }\end{array}$ & $\begin{array}{l}\text { Automatic } \\
\text { material } \\
\text { handling } \\
(7)\end{array}$ & $\begin{array}{c}\text { Inspection } \\
\text { and } \\
\text { communications } \\
\text { (8) }\end{array}$ \\
\hline Improvement in productivity & 70.1 & 75.9 & 77.4 & 54.6 & 56.0 & 55.7 & 54.2 & 34.3 \\
\hline Reduction in labour requirements & 48.6 & 72.1 & 50.0 & 31.5 & 35.3 & 47.6 & 54.2 & 21.7 \\
\hline Reduction in material consumption & 19.0 & 34.1 & 15.0 & 13.8 & 17.2 & 24.0 & 15.2 & 10.7 \\
\hline Reduction in energy consumption & 9.8 & 24.3 & 7.7 & 11.7 & 7.3 & 15.1 & 8.7 & 6.6 \\
\hline Increase in equipment utilization & 29.5 & 43.3 & 56.3 & 29.3 & 13.0 & 23.8 & 20.2 & 12.4 \\
\hline Increase in capital requirements & 33.2 & 52.6 & 58.6 & 30.1 & 25.6 & 35.2 & 27.3 & 18.8 \\
\hline Reduction in capital investment & 3.9 & 6.1 & 5.6 & 3.0 & 3.0 & 4.7 & 3.7 & 1.5 \\
\hline Reduction in inventory & 9.3 & 43.2 & 20.2 & 22.1 & 8.0 & 22.0 & 23.0 & 9.7 \\
\hline Improvement in product quality & 46.7 & 65.2 & 56.8 & 51.2 & 43.1 & 52.9 & 32.6 & 33.7 \\
\hline Reduction in product rejection & 18.3 & 57.8 & 52.6 & 41.3 & 20.9 & 39.9 & 24.2 & 22.5 \\
\hline Reduction in set-up time & 38.7 & 51.2 & 46.4 & 11.0 & 26.8 & 38.7 & 19.6 & 10.8 \\
\hline Increase in product flexibility & 37.4 & 48.7 & 52.5 & 19.0 & 30.1 & 32.2 & 18.3 & 12.7 \\
\hline Improvement in working conditions & 28.5 & 43.8 & 58.5 & 19.2 & 18.0 & 33.5 & 29.8 & 15.2 \\
\hline $\begin{array}{l}\text { Reduction in environmental } \\
\text { damage }\end{array}$ & 5.3 & 26.2 & 7.4 & 11.2 & 8.4 & 15.7 & 11.6 & 8.4 \\
\hline Increase in skill requirements & 54.2 & 56.0 & 58.8 & 47.2 & 34.0 & 32.4 & 25.1 & 26.4 \\
\hline Reduction in skill requirements & 8.2 & 15.8 & 5.0 & 5.6 & 4.8 & 9.7 & 7.6 & 3.1 \\
\hline
\end{tabular}

Note: Benefits and effects are not mutually exclusive; neither is the use of groups of technologies.

Source: Baldwin, Sabourin and Rafiquzzaman (1996). 


\subsection{Impediments to Advanced Technology Adoption}

The impediments that were investigated in the SIAT survey can be divided into five groups. The first includes a set of general cost-related problems associated with advanced technology adoption, including the cost of capital, the cost of technology acquisition, the cost of related equipment acquisition, the cost of related software development, and increased maintenance expenses.

Four other areas were also identified-impediments that arise from government policy (what we call institutional-related problems), from labour market imperfections, from internal organization problems and from imperfections in the market for information. Each of these also increases the costs of adopting advanced technology — but the causes are somewhat more narrowly focused than the general cost-related items that are included in the first category.

Labour-related problems include difficulties that arise because new technologies and innovation generally need higher skill levels (Baldwin, Gray and Johnson, 1996; Baldwin and Da Pont, 1996). In the face of these needs, a firm may encounter impediments to adoption if there is a shortage of skills available on the market, or if it faces training difficulties in overcoming deficiencies, or if its labour contracts act to constrain its ability to substitute labour across tasks.

Organizational problems are those associated with difficulties in implementing the types of internal change in a firm that are required for the adoption of advanced technologies. The first of these is the difficulty in introducing important changes to the organization. For example, the introduction of computer-aided design may require new structures that link engineering development with the production department so that the advantages of concurrent engineering practices can be fully exploited. Other organizational problems stem from a poor attitude of senior management towards new technologies, or worker resistance.

Institution-related problems are those associated with tax regimes (both the R\&D tax credit and capital cost allowances) and with government regulations and standards. Information-related problems arise if markets for knowledge are imperfect.

They include lack of scientific and technical information, technological services, and technical support from vendors.

Table 4 reports the percentage of plant managers who reported that these problems impeded the adoption of advanced technologies. Two measures of technological activity are used to examine differences in the impediments faced by the more technologically active. First, we report the percentage of technology users and technology non-users that reported the impediment, where a technology user is defined as a plant that uses any of the 22 advanced technologies. We also divide the sample of plants into those whose parent company reported an innovation (defined as the introduction of a new product or process) in the three year period prior to the survey and those who did not report an innovation during that period. Columns 1 to 5 contain the percent of shipments in plants reporting a particular impediment; Columns 6 to 10 the percentage of 
establishments (duly weighted to represent the manufacturing population) reporting that they experienced the particular impediment. The importance given to the impediments will differ in the first panel (Columns 1 to 5) from the second panel (Columns 6 to 10) if larger firms are more likely to designate an impediment as important.

Among the five broad groups of impediments, general cost-related problems are the most important and most frequently reported by firms. Economics is at work in the innovation process in that broad generic classes of costs like equipment and capital are seen to have an impact on the investment decision. Contributory cost factors (in order of importance) are cost of equipment, cost of capital investment, cost of technology acquisition, cost of software development, and maintenance expenses. Over two-thirds of establishments encountered at least one of these impediments, accounting for nearly $80 \%$ of all manufacturing shipments. Whether we use the percentage of establishments (Column 6) or the share of shipments (Column 1), the rankings of these factors are about the same, thereby indicating that large and small firms place about equal emphasis on these general cost-related impediments.

Labour-related problems, stemming from skill shortages, training difficulties or labour contracts, are the area where specific problems are most important. Some $29 \%$ of establishments reported them as impediments. Shipments from establishments that experienced at least one of these difficulties amounted to $37 \%$ of total manufacturing output.

The next most important group are organization-related problems caused by difficulties in introducing important changes to the organization, management attitude and worker resistance. One out of every five firms experienced one of these problems. Contrary to the other categories however, the share of shipments in plants reporting this problem (34\%) is significantly higher than the percentage of establishments with the problem $(21 \%)$, thereby indicating that larger establishments are more likely to have these problems.

The least important category of impediments consists of institution-related problems (associated with the R\&D investment tax credit, capital cost allowance and government regulations) and information-related problems (such as lack of scientific and technical information, lack of technological services and lack of technical support from vendors).

If impediments are the primary deterrents to technology use and innovation, it might be expected that non-users and non-innovators would report higher impediments. This is not the case. With rare exceptions, the percentage of users reporting impediments is markedly and consistently higher than among non-users; it is also more frequent among innovators than non-innovators. 
Table 4. Impediments to Advanced Technology Adoption

\begin{tabular}{|c|c|c|c|c|c|c|c|c|c|c|}
\hline \multirow[b]{2}{*}{ Impediment } & \multicolumn{5}{|c|}{$\%$ of Shipments } & \multicolumn{5}{|c|}{$\%$ of Establishments } \\
\hline & $\begin{array}{c}\text { All } \\
\text { firms } \\
(1)\end{array}$ & $\begin{array}{c}\text { Technology } \\
\text { user } \\
(2)\end{array}$ & $\begin{array}{c}\text { Non- } \\
\text { user } \\
(3)\end{array}$ & $\begin{array}{c}\text { Innovator } \\
(4) \\
\end{array}$ & $\begin{array}{c}\text { Non- } \\
\text { innovator } \\
(5) \\
\end{array}$ & $\begin{array}{c}\text { All } \\
\text { firms } \\
(6)\end{array}$ & $\begin{array}{c}\text { Technology } \\
\text { user } \\
(7)\end{array}$ & $\begin{array}{l}\text { Non- } \\
\text { user } \\
(8)\end{array}$ & $\begin{array}{c}\text { Innovator } \\
\text { (9) }\end{array}$ & $\begin{array}{c}\text { Non- } \\
\text { innovator } \\
(10) \\
\end{array}$ \\
\hline Cost-related & 79.1 & 83.5 & 58.7 & 82.9 & 66.4 & 68.5 & 76.9 & 63.1 & 72.6 & 65.9 \\
\hline Capital & 49.2 & 50.7 & 42.1 & 49.8 & 46.9 & 47.0 & 48.9 & 45.7 & 47.6 & 46.6 \\
\hline Equipment & 56.4 & 58.6 & 46.1 & 59.6 & 45.6 & 53.0 & 58.8 & 49.3 & 56.7 & 50.8 \\
\hline Software development & 21.8 & 23.6 & 12.9 & 21.6 & 22.4 & 17.5 & 22.9 & 14.1 & 21.1 & 15.4 \\
\hline Maintenance & 13.3 & 14.0 & 10.1 & 14.1 & 10.7 & 12.4 & 12.8 & 12.1 & 12.2 & 12.5 \\
\hline Technology acquisition & 28.8 & 30.1 & 23.1 & 30.1 & 24.6 & 27.9 & 28.1 & 27.8 & 26.9 & 28.5 \\
\hline Institution-related & 15.5 & 15.9 & 13.2 & 16.5 & 11.9 & 16.4 & 16.6 & 16.4 & 18.6 & 15.1 \\
\hline $\mathrm{R} \& \mathrm{D}$ investment tax credit & 7.6 & 8.0 & 5.8 & 8.7 & 3.8 & 7.7 & 9.8 & 6.4 & 11.7 & 5.3 \\
\hline Capital cost allowance & 8.7 & 9.5 & 4.9 & 9.7 & 5.0 & 8.4 & 9.5 & 7.6 & 9.9 & 7.4 \\
\hline Regulations and standards & 7.2 & 7.4 & 6.3 & 6.8 & 8.4 & 9.9 & 8.1 & 11.1 & 9.3 & 10.3 \\
\hline Labour-related & 37.2 & 39.9 & 24.2 & 39.0 & 30.9 & 28.8 & 34.5 & 25.2 & 33.7 & 25.8 \\
\hline Skill shortage & 22.8 & 24.3 & 15.7 & 24.0 & 18.7 & 20.2 & 22.7 & 18.6 & 23.3 & 18.3 \\
\hline Training difficulty & 19.3 & 20.7 & 12.8 & 19.8 & 17.5 & 16.8 & 20.5 & 14.4 & 18.0 & 16.0 \\
\hline Labour contract & 13.0 & 14.2 & 7.3 & 13.4 & 11.3 & 5.8 & 7.2 & 4.9 & 7.2 & 4.9 \\
\hline Organization-related & 34.1 & 37.3 & 18.9 & 35.9 & 28.1 & 20.9 & 26.1 & 17.7 & 24.9 & 18.5 \\
\hline Difficulty in introducing change & 23.3 & 25.7 & 11.9 & 25.4 & 16.2 & 13.0 & 15.9 & 11.1 & 17.2 & 10.4 \\
\hline Management attitude & 16.7 & 18.5 & 8.3 & 16.8 & 16.4 & 7.9 & 9.4 & 7.0 & 9.2 & 7.2 \\
\hline Worker resistance & 11.0 & 11.3 & 9.4 & 11.5 & 8.9 & 9.0 & 10.7 & 7.9 & 9.8 & 8.5 \\
\hline Information-related & 24.9 & 26.6 & 16.8 & 27.2 & 17.1 & 16.0 & 19.6 & 13.7 & 22.0 & 12.3 \\
\hline Lack of information & 12.4 & 12.3 & 12.9 & 12.9 & 10.7 & 10.4 & 10.5 & 10.4 & 13.3 & 8.7 \\
\hline Lack of service & 9.8 & 10.1 & 8.3 & 10.4 & 7.7 & 7.7 & 8.2 & 7.4 & 10.4 & 6.0 \\
\hline Lack of support from vendors & 10.9 & 11.3 & 8.8 & 11.5 & 8.8 & 8.6 & 11.0 & 7.1 & 12.1 & 6.4 \\
\hline
\end{tabular}

Note: Impediment groups as well as sub-group components are not mutually exclusive. Group-level results refer to incidence of experiencing any of the impediments within the group. 
A learning-by-doing model of technology adoption can explain this phenomenon. Firms have to assess the benefits of implementing technological changes. Firms that are innovative reap substantial benefits as we have already demonstrated. In order to reap those benefits, they have to incur the higher costs of new equipment and of research and development facilities. Other research has shown that there are many types of costs that are higher for technology users and innovators. For one, more technologically advanced firms find that their skill requirements increase after new technologies are introduced (Baldwin, Gray and Johnson, 1996). Training is more likely in firms that are high-tech users or innovators (Baldwin, 1999). Moreover, firms that are innovators are more likely to be developing greater competencies in other areas besides just human resources. Baldwin and Johnson (1996 and 1999) show that more innovative firms (especially those that introduced new products and new processes) develop greater competencies in a wide range of areas. They gain more from their high-risk innovation strategy, but they risk more and they incur higher costs because they have to master a wider range of competencies.

Therefore, when we compare users and non-users, we are dealing with two very different populations. Technology users or innovative firms have been exposed to the problems that come with an innovative strategy. Before adopting new technologies, firms have a basic understanding of the problems that they will face. This impression is correct only with regards to the broad overview of the relative importance of the different problems that they face. As proof of this, the relative ranking for users and non-users is quite similar-the correlation between the scores of users and non-users or innovators and non-innovators (whether using percentage of establishments or percentage of shipments is over 0.95). But the level of impediments is generally lower for non-users or for non-innovators. It is by attempting an innovative or technologically advanced strategy that a firm learns about the true intensity of the problems that it has to solve.

The one area where differences between technology users and non-users are generally smaller is with respect to government policy. When it comes to assessing the usefulness of R\&D subsidy programs or the problems with government regulations, non-users are able ex ante to better assess the likelihood that government activity will benefit or restrict them.

In summary, we should expect a more advanced technology strategy to lead to more impediments being reported. While differences in impediments between technology users and non-users may be explained in the context of the learning-by-doing process of technology adoption, there are other factors that may come into play that need to be examined within a multivariate framework. Previous work has shown that there are inherent differences in terms of certain firm characteristics between technology users and non-users; and between innovating firms and noninnovating ones. ${ }^{5}$ It may be that these characteristics also contribute to the observed differences in impediments. In the next section, we ask whether differences in the impediments persist after controlling for firm characteristics.

\footnotetext{
${ }^{5}$ For example, Baldwin and Diverty (1995) have shown that technology use is positively associated with firm size and output growth; the tendency for larger firms to be more innovative is also well documented (e.g., Baldwin, Gellatly, Johnson and Peters (1998); Evangelista and Sirilli (1997); Cosh, Hughes and Wood (1996)).
} 


\section{Determinants of Impediments to Advanced Technology Adoption}

To examine the factors that are associated with impediments, we use multivariate analysis to relate the probability of reporting an impediment to whether a plant is technologically advanced and a set of plant characteristics, such as size, growth, region, and degree of innovativeness.

The regressions are performed for each of the five major groups of impediments: cost-related, institution-related, labour-related, organization-related, and information-related. For each group, the dependent variable takes a value of one if a plant reports any of the problems within the group; the value of zero otherwise. Since the dependent variable is dichotomous, we estimate the relationship with a logistic regression. ${ }^{6}$

\subsection{Alternative Measures of Technologic and Innovative Activity}

Four different measures of technological activity are used to test the robustness of our hypothesis that impediments are higher in more technological advanced or more innovative firms.

The first is USER - whether the plant uses advanced technology in the production process at all. This is a dichotomous variable taking a value of one if the plant uses any of the 22 technologies and zero otherwise. This measure distinguishes technology users from non-users but does not take into account the intensity of technology use.

The second-TECHUSE-measures the total number of advanced technologies in use. This is a continuous variable reflecting the total number of advanced technologies that a firm uses and it ranges in value from 0 to 22 . This measure takes into account the intensity of technology use. Its form imposes a monotonic relationship between the number of technologies in use and the probability of reporting an impediment.

The third consists of a set of binary variables capturing different intensities- 0,1 to 4,5 to 9 and 10 and more technologies. This measure takes into account the intensity of technology use and it allows for the possibility of a non-linear impact of the number of technologies that are used.

It should be noted that the first three measures essentially nest within each other, thereby allowing us to test whether capturing intensity as opposed to incidence of use matters.

Finally, the fourth variable-INNOV-measures whether the plants were innovative. This variable is broader than just the technology use variable. Innovative activities are measured by a dichotomous variable indicating if the plant's controlling firm introduced either a major product or process innovation in the three years prior to the survey.

\footnotetext{
${ }^{6}$ Probit analysis, an alternative for dichotomous dependent variables, was tried and resulted in the same qualitative results.
} 


\subsection{Plant Characteristics}

Certain plant characteristics have been shown to be closely related to whether technology is used (Baldwin and Diverty, 1995) or whether a firm is innovative (Baldwin, Hanel and Sabourin, 2001). These include region, industrial sector, intensity of competition, age, output growth patterns, ownership, size and unionization.

These variables are included because they are expected to represent aspects of technology use that are not captured by the technology variables used. While we include variables such as USER or TECHUSE that measure the amount of technology use, these variables cannot completely capture the complexity or sophistication of the actual technological environment. Since larger, younger and foreign-controlled plants are more likely to use any technology (Baldwin and Diverty, 1995; Baldwin and Sabourin, 1997), we expect that plants with these characteristics are more technologically advanced in many dimensions and, therefore, should be more likely to report an impediment. Size of the establishment is measured by four binary variables capturing the number of employees: under 20, 20 to 99, 100 to 499, and 500 and over. Age of the firm is measured by three binary variables: born prior to 1975, between 1975 and 1984, and after 1984 .

We also include regional binary variables to capture the same technological-intensity phenomenon. The incidence of advanced technology use is less in Atlantic Canada and Quebec relative to other provinces (Baldwin and Sabourin, 1995) and, therefore, the overall technical sophistication of these regions should also be reflected in generally lower impediments. Five economic regions are used in the regression analysis: Atlantic Canada consists of Newfoundland, Prince Edward Island, Nova Scotia and New Brunswick; Quebec; Ontario; the Prairie provinces, which includes Manitoba, Saskatchewan and Alberta; and British Columbia.

Growth of the plant is included for three reasons. First, growth is a measure of success and success is highly correlated with the degree of innovativeness in a firm (Baldwin, 1996; Baldwin and Johnson, 1998). Although we capture major innovations with INNOV, there are other more minor aspects that are omitted and that the growth variable is meant to represent. Therefore, we should expect growth to be positively related to impediments. Second, growing firms are technological sophisticated (Baldwin and Diverty, 1995). Third, growth itself leads to problems. Growing firms have to learn how to deal with the problems associated with larger size. Growing organizations have to change. New labour skills associated with running a larger firm are required. These problems are likely to be particularly severe in the area of labour impediments. Output growth patterns are measured as the change in a plant's manufacturing shipments over the 10-year period from 1982 to 1992. Ranking firms according to their growth in shipments during this period, we create three growth classes with an equal number of firms in each class. These are low or negative growth, medium growth, and high growth. Nationality of ownership is represented by a binary variable, CANADIAN, that takes a value of one if the plant's parent indicated that it was controlled by Canadians and zero, otherwise. 
The importance of unionization in a plant is also posited to be related to impediments - though not necessarily because of any connection to technological sophistication. Rather it is included because it is sometimes seen as a factor that would make technology adoption more difficult because it increases the costs to management of changing work patterns during the introduction of new technological processes. Unionization is a binary variable that takes on a value of one if the parent firm reports that any of its employees are covered by a collective agreement.

We also posit that the environment within which a plant operates will affect the nature of the impediments that are encountered. The first characteristic that we consider is whether the industry environment is advanced with regards to the degree of innovation being produced. Some industries are more innovative and, therefore, plants in these industries are more likely to face impediments. The innovative environment is captured with an industry taxonomy developed by Robson, Townsend and Pavitt (1988) that has been used successfully in research that explains the probability that a firm will innovate (Baldwin, Hanel and Sabourin, 2001). Firms are classified into three sectors according to their industrial activities: core innovative sector, secondary innovative sector, and other innovative sector. ${ }^{7}$ The core sector is the one that has been found in work for the UK and the US (Robson, Townsend and Pavitt, 1988) and for Canada (Baldwin and Hanel, 2002) to be the sector that produces more innovations than it uses. The "other" sector ingests new products and machinery and equipment from the core and secondary sectors. If production of an innovation rather than its adoption is a signal of sophistication, we should expect the core, secondary and "other" sectors to rank in this order with regards to the probability of reporting an impediment.

The second environmental characteristic that is posited to affect the development of impediments is the competitive environment. Competition is important in that it affects innovation or technological competencies. Elsewhere, we have found that there is a positive relationship between competition and innovation (Baldwin, Hanel and Sabourin, 2001). The intensity of competition that a firm faces is measured by the number of rivals directly competing in the marketplace for the sale of its main product(s): 0 to 5 competitors, 6 to 19 competitors, and 20 or more competitors. More detail on variables, as well as sample statistics, are reported in Table 5.

\subsection{Empirical Results}

The regression results for the probability of reporting impediments in each of the five major areas are reported in Table 6 . The coefficients are all calculated against the omitted category-which is a plant that did not use advanced technologies, did not introduce innovation, was located in Ontario, was in the "other" innovation using sector, faced the smallest number of competitors (5 or less), was born before 1975, was a slow grower, was foreign-owned, was in the smallest size class (less than 20 employees), and whose employees were not unionized. The regressions are estimated on a sample of 1,936 establishments. Column 1 contains the estimates for cost-related

\footnotetext{
${ }^{7}$ The core innovative sector includes refined petroleum, chemical, electrical and electronic industries; the secondary innovative sector includes fabricated metals, rubber and plastics, transportation equipment, primary metals, and nonmetallic minerals; the other innovative sector includes paper, wood, food and beverages, textile and clothing, printing and publishing, furniture and fixture, and other manufacturing industries.
} 
problems; Column 2 for institution-related problems; Column 3 for labour-related problems; Column 4 organization-related problems; and Column 5 for information-related problems. In this table, we measure technology use by the range of number of technologies in use. Results for other measures-incidence of technology use, intensity of technology use, and an interactive term between using technology and being an innovator are presented in Appendix Tables A1 through A3. Table A1 reports the regression results when technology use is measured by a single dummy variable indicating whether a firm uses advanced technology or not; Table A2 when technology use is measured by the actual number of technologies used; and Table A3 when firm activities are measured by the interaction between technology use and innovation-non-user noninnovator, non-user innovator, user non-innovator, and user innovator.

The parameter estimates in Table 6 show the qualitative impacts of the explanatory variables. To better describe the quantitative impacts of each of the variables, we report in Table 7 the probability that each of the five advanced technology adoption impediments will occur. These probabilities are estimated using the regression results presented in Table 6, evaluated at the sample mean values. ${ }^{8}$ Again, Column 1 contains estimates for cost-related problems; Column 2 for institution-related problems; Column 3 for labour-related problems; Column 4 for organization-related problems; and Column 5 for information-related problems.

The results demonstrate that technology use is positively associated with impediments in almost all areas. From Table 6, we can see that those plants reporting the use of 10 or more technologies are significantly more likely to have faced cost impediments, institutional impediments, labour impediments, and information impediments. When only incidence is used (USER), a significant effect is found for cost-related, labour and organization problems (Table A1). When intensity of technology use (TECHUSE) is included, a significant effect is found for cost-related, and labour problems (Table A2).

Innovators are found to report significantly greater institutional, and information impediments. When technology users are divided into innovators and non-innovators (Table A3), the innovators are found to have a greater likelihood than non-innovators of reporting impediments for institutional and informational impediments. But what is most significant is that the combination of being a technology user and an innovator is significantly related to all impediments. Firms that are using advanced technologies and reporting an active innovation program are solving more complex, more comprehensive technological problems. That this group is most likely to report impediments in all areas lends support to our hypothesis that impediments are realized as a firm implements a complex innovation strategy.

The effect of the intensity of technology use can be quite large. For example, other things being equal (evaluating at the mean value), the probability of a plant reporting cost-related problems is estimated to be $89 \%$ among plants that use 10 or more technologies compared to $66 \%$ among non-users (Table 7) —an increase of over 20 percentage points. For institution-related problems, it increases from $14 \%$ to $29 \%$. By way of comparison, going from non-innovative to innovative status increases the probability of facing institution-related impediments from $13 \%$ to $17 \%$. The

${ }^{8}$ The logistic regression model is $\operatorname{Ln}[\mathrm{P} /(1-\mathrm{P})]=\beta \mathrm{X}$, it follows that $\mathrm{P}=\exp (\beta \mathrm{X}) /[1+\exp (\beta \mathrm{X})]$, where $\mathrm{P}$ is the probability. 
probability of reporting labour-related impediments increases by about 15 percentage points between non-users and users of 10 or more technologies; and the probability of reporting information-related impediments differs by 7 percentage points. The effect of being an innovator is 8 percentage points in the case of information-related impediments.

These results then demonstrate both a certain commonality, but they also show that the determinants of the impediments vary from one group to another. This is the case for most of the other variables.

Other important plant characteristics affecting several areas include the intensity of competition a plant faces, and the age of a firm. Specifically, for cost-, labour- and information-related problems, the more competitors a firm faces, the higher the likelihood it faces such problems. The probability of cost-related problems is 10 percentage points higher for those that face 20 or more competitors than for those facing 0 to 5 competitors ( $75 \%$ versus $65 \%$ ). The difference is 8 and 5 percentage points for labour- and information-related problems. This confirms our hypothesis that the effect of competition arises because competition engenders more technological competencies.

There are also substantial regional effects that accord with our technological intensity hypothesis. Firms in Atlantic Canada and Quebec report significantly fewer cost- and labour-related problems than they were expected to do-based on their lower technology use. There is about 10 percentage points difference between firms located in Atlantic Canada and in Ontario for costrelated impediments.

Younger plants are also more likely to experience cost-, institutional- and labour-related problems. Some $77 \%$ of those born after 1984 face cost-related problems compared to $64 \%$ of those born prior to 1975 . Younger firms face about 10 percentage points difference ( $26 \%$ versus $16 \%$ ) for labour-related problems and a 7 percentage points difference (18\% versus $11 \%)$ for information-related problems. Since younger plants are more likely to be advanced technology users, the positive relationship between youth and impediments also accords with our maintained hypothesis.

Unionization significantly increases the probability of labour and organizational impediments. A plant that reports its employees are covered by a collective agreement increases its probability of reporting impediments in each of these areas by about 3 to 5 percentage points; but this is a relatively small effect compared to most of the other variables.

Growth has the expected effect on labour-related problems. Plants that are faster growers are likely to report more labour-related problems. The difference between the slowest and fastest growing categories is 6 percentage points. Another variable that has little impact on impediments is the innovation sector within which a plant finds itself. Thus, there is little to distinguish innovation-producing from innovation-using sectors in terms of the impediments that are faced. 
There is generally no significant effect of ownership on the probability that an impediment is reported-except in the area of information flows. Even here the effect is relatively small—only 4 percentage points.

How do the various impediment categories compare? For cost-related impediments, technology use, region, competition, age, and growth matter. Institution-related problems are likely to be higher when a firm uses multiple advanced technologies, performs innovative activities, is in Ontario, in the core sector, has more competitors, and is younger. Compared to cost-related problems, innovation matters more when firms assess whether the government programscapital cost allowance, R\&D assistance and regulation - provide impediments.

For labour-related problems, the general pattern that was observed for cost- and institutionrelated problems holds. Technology use is important-as is competition, age, and region. The younger the firm is, the higher is the likelihood of labour-related problems (the probability is $26 \%$ for those born since 1985, 21\% for those born between 1975 and 1984, and 16\% for those born before 1975). Similarly, faster growing firms are more likely to experience labour-related problems (the probability is $24 \%$ for those experiencing medium to high growth compared to $18 \%$ for those experiencing low or negative growth). Once again, marked regional differences are observed-establishments located in Atlantic Canada and Quebec have a probability of $18 \%$ and $14 \%$ of experiencing labour-related problems compared to $26 \%$ for those located in the rest of the country. In contrast to the cost and institution-related areas, unionization is important for labour-related problems.

There are fewer significant determinants of organization-related problems than in the case of either cost-, institutional- or labour-related problems. Region, competition and age matter here as elsewhere, but the effect of technology use is less; innovation combined with technology use becomes significant-thereby suggesting that organizational problems are more important in firms that have adopted a complex technology/innovation strategy. Size is more important here than it was for the other categories, but it is the medium-sized plants not the largest ones that are more likely to report impediments. Unionization increases organizational impediments, one of which is worker resistance to change.

Information-related problems also are characterized by the common technology, competition and age variables. But here innovation by itself is significant and when interacted with technology use (Table A3). What is also unique about this category is that Canadian-owned plants face significantly more impediments when it comes to information problems, while this does not occur for the other categories. 
Table 5. Variable Definition and Sample Statistics

\begin{tabular}{|c|c|c|c|}
\hline Variable & Definition & Means & Std. Dev. \\
\hline COSTPROB & $=1$ if any cost-related problem is reported & 0.6848 & 0.4647 \\
\hline INSTPROB & $=1$ if any institution-related problem is reported & 0.1644 & 0.3707 \\
\hline LABOPROB & $=1$ if labour-related problem is reported & 0.2883 & 0.4531 \\
\hline ORGAPROB & $=1$ if any organization-related problem is reported & 0.2095 & 0.4071 \\
\hline INFOPROB & $=1$ if any information-related problem is reported & 0.1598 & 0.3665 \\
\hline USER & $=1$ if any technology is used & 0.3886 & 0.4876 \\
\hline TECH USE & $=$ Total number of technologies used & 1.5936 & 2.8457 \\
\hline \multicolumn{4}{|l|}{ Number of tech use: } \\
\hline $1-4$ & $=1$ if $1-4$ technologies are used & 0.2509 & 0.4337 \\
\hline $5-9$ & $=1$ if $5-9$ technologies are used & 0.1047 & 0.3062 \\
\hline $10+$ & $=1$ if $10+$ technologies are used & 0.0330 & 0.1786 \\
\hline \multicolumn{4}{|l|}{ Use of functional tech: } \\
\hline DE tech & $=1$ if any design and engineering technology is used & 0.2734 & 0.4458 \\
\hline FA tech & $=1$ if any fabrication and assembly technology is used & 0.1855 & 0.3888 \\
\hline AMH tech & $=1$ if any automatic material handling technology is used & 0.0313 & 0.1741 \\
\hline IC tech & $=1$ if any inspection and communication technology is used & 0.2174 & 0.4126 \\
\hline Innovator & $=1$ if any innovating activity is introduced & 0.3804 & 0.4856 \\
\hline \multicolumn{4}{|c|}{ 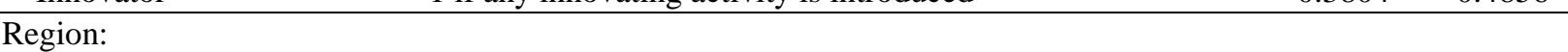 } \\
\hline Atlantic & $=1$ if locates in Atlantic Canada & 0.0487 & 0.2153 \\
\hline Quebec & $=1$ if locates in Quebec & 0.3182 & 0.4659 \\
\hline Ontario & $=1$ if locates in Ontario & 0.3958 & 0.4892 \\
\hline Prairie & $=1$ if locates in the Prairie provinces & 0.1522 & 0.3593 \\
\hline British Columbia & $=1$ if locates in British Columbia & 0.0851 & 0.2792 \\
\hline \multicolumn{4}{|l|}{ Industrial sector: } \\
\hline Core innovative & $=1$ if one of the core innovative industries & 0.1554 & 0.3624 \\
\hline Secondary innovative & $=1$ if one of the secondary innovative industries & 0.3080 & 0.4618 \\
\hline Other innovative & $=1$ if one of the other innovative industries & 0.5366 & 0.4988 \\
\hline \multicolumn{4}{|l|}{ Number of competitors: } \\
\hline $0-5$ & $=1$ if facing $0-5$ competitors & 0.2841 & 0.4511 \\
\hline $6-19$ & $=1$ if facing $6-19$ competitors & 0.3042 & 0.4602 \\
\hline $20+$ & $=1$ if facing $20+$ competitors & 0.4117 & 0.4923 \\
\hline \multicolumn{4}{|l|}{ Year of birth: } \\
\hline Prior to 1975 & $=1$ if born before 1975 & 0.2918 & 0.4547 \\
\hline $1975-1984$ & $=1$ if born between 1975 and 1984 & 0.2908 & 0.4543 \\
\hline After 1984 & $=1$ if born after 1984 & 0.4174 & 0.4933 \\
\hline \multicolumn{4}{|l|}{ Output growth patterns: } \\
\hline Low & $=1$ if experiencing low shipment growth & 0.3507 & 0.4773 \\
\hline Medium & $=1$ if experiencing medium shipment growth & 0.4239 & 0.4943 \\
\hline High & $=1$ if experiencing high shipment growth & 0.1987 & 0.3991 \\
\hline Canadian & $=1$ if owned by Canadians & 0.8798 & 0.3252 \\
\hline \multicolumn{4}{|l|}{ Number of employees: } \\
\hline $1-19$ & $=1$ if $1-19$ employees & 0.5177 & 0.4998 \\
\hline $20-99$ & $=1$ if $20-99$ employees & 0.3446 & 0.4754 \\
\hline $100-499$ & $=1$ if $100-499$ employees & 0.1204 & 0.3256 \\
\hline $500+$ & $=1$ if $500+$ employees & 0.0172 & 0.1301 \\
\hline Union & $=1$ if employees are unionized & 0.2917 & 0.4547 \\
\hline Number of observations & & 1936 & \\
\hline
\end{tabular}

Note: Sample statistics are weighted by the establishment weight. 
Table 6. Logistic Regression Results for Reporting Technology Adoption Impediments

\begin{tabular}{|c|c|c|c|c|c|c|c|c|c|c|}
\hline \multirow[t]{2}{*}{ Indep. Var. } & \multicolumn{2}{|c|}{$\begin{array}{c}\text { Dep. Var. }=\text { Costprob } \\
\text { (1) }\end{array}$} & \multicolumn{2}{|c|}{$\begin{array}{c}\text { Dep. Var. = Instprob } \\
\text { (2) }\end{array}$} & \multicolumn{2}{|c|}{$\begin{array}{c}\text { Dep. Var. = Laboprob } \\
\text { (3) }\end{array}$} & \multicolumn{2}{|c|}{$\begin{array}{c}\text { Dep. Var. = Orgaprob } \\
\text { (4) }\end{array}$} & \multicolumn{2}{|c|}{$\begin{array}{c}\text { Dep. Var. = Infoprob } \\
\text { (5) }\end{array}$} \\
\hline & Coefficient & T-ratio & Coefficient & T-ratio & Coefficient & T-ratio & Coefficient & T-ratio & Coefficient & T-ratio \\
\hline $1-4$ tech use & 0.6320 & 4.80 & -0.1897 & -1.16 & 0.1665 & 1.30 & 0.2015 & 1.43 & 0.0610 & 0.37 \\
\hline $5-9$ tech use & 0.5623 & 2.84 & 0.0731 & 0.32 & 0.2337 & 1.27 & 0.2209 & 1.10 & 0.6219 & 2.9 \\
\hline $10+$ tech use & 1.3727 & 3.22 & 0.9125 & 2.62 & 0.7218 & 2.38 & 0.4455 & 1.40 & 0.5691 & 1.6 \\
\hline Innovator & 0.1558 & 1.30 & 0.3297 & 2.25 & 0.1555 & 1.30 & 0.0813 & 0.62 & 0.6460 & 4.38 \\
\hline Atlantic & -0.5790 & -2.50 & -1.2703 & -3.18 & -0.5121 & -1.96 & -0.6865 & -2.09 & 0.3317 & 1.11 \\
\hline Quebec & -0.2243 & -1.79 & -1.0762 & -6.35 & -0.7705 & -5.71 & -0.1232 & -0.87 & 0.0919 & 0.57 \\
\hline Prairie & 0.1437 & 0.90 & -0.5582 & -2.88 & -0.0762 & -0.50 & 0.0903 & 0.53 & 0.4510 & 2.43 \\
\hline British Columbia & 0.0175 & 0.09 & -0.2143 & -0.96 & 0.0890 & 0.48 & -0.3519 & -1.52 & -0.1640 & -0.63 \\
\hline Core sector & 0.0061 & 0.04 & -0.3420 & -1.69 & 0.1179 & 0.75 & -0.1585 & -0.92 & 0.2859 & 1.56 \\
\hline Secondary sector & -0.1780 & -1.54 & -0.0622 & -0.43 & 0.1095 & 0.92 & -0.2655 & -1.97 & 0.0276 & 0.18 \\
\hline 6-19 competitors & 0.3797 & 2.89 & 0.4303 & 2.53 & 0.2288 & 1.62 & 0.1603 & 1.04 & 0.3961 & 2.27 \\
\hline $20+$ competitors & 0.4832 & 3.88 & 0.1729 & 1.05 & 0.4489 & 3.38 & 0.2898 & 1.98 & 0.4292 & 2.56 \\
\hline Born 1975-1984 & 0.3280 & 2.33 & -0.0453 & -0.23 & 0.3492 & 2.29 & 0.2916 & 1.81 & -0.0516 & -0.27 \\
\hline Born after 1984 & 0.6805 & 4.91 & 0.5428 & 3.05 & 0.6056 & 4.09 & 0.1719 & 1.08 & 0.5053 & 2.88 \\
\hline Medium growth & 0.0164 & 0.14 & 0.2961 & 2.05 & 0.3366 & 2.76 & 0.0666 & 0.49 & -0.1068 & -0.71 \\
\hline High growth & -0.2579 & -1.46 & 0.0592 & 0.26 & 0.3447 & 1.96 & 0.1733 & 0.93 & 0.1237 & 0.59 \\
\hline Canadian-owned & 0.2579 & 1.42 & -0.0045 & -0.02 & 0.1148 & 0.65 & -0.1523 & -0.83 & 0.3817 & 1.73 \\
\hline 20-99 employees & -0.1002 & -0.75 & -0.4053 & -2.42 & -0.0588 & -0.43 & 0.1328 & 0.88 & -0.0792 & -0.46 \\
\hline 100-499 employees & 0.6225 & 2.54 & -0.4448 & -1.50 & 0.3909 & 1.71 & 0.5630 & 2.32 & 0.0390 & 0.14 \\
\hline 500+ employees & 0.5948 & 1.08 & -1.3722 & -2.09 & 0.3599 & 0.80 & 0.5632 & 1.22 & -0.2321 & -0.44 \\
\hline Union & 0.1007 & 0.80 & 0.1977 & 1.27 & 0.2094 & 1.65 & 0.2975 & 2.19 & 0.1334 & 0.86 \\
\hline Constant & -0.3147 & -1.29 & -1.6852 & -5.40 & -1.9094 & -7.47 & -1.7711 & -6.60 & -3.0828 & -9.60 \\
\hline
\end{tabular}

\section{Summary statistics:}

n (Dep. Var. = 1)

LL function

$\chi^{2}$

\begin{tabular}{c}
1936 \\
558 \\
-1106.5 \\
112.6 \\
71.6 \\
\hline
\end{tabular}

1936
406
-961.4
64.6
79.0

1936

1936
318
-814.8
100.6
83.6

Note: The reference groups are firms using no advanced technology, performing no innovative activities, located in Ontario, belonging to the "other" industrial sector, facing 0-5 competitors, born prior to 1975, experiencing low output growth, owned by foreigners, with 1-19 employees, and employees are not unionized. Critical values for $t$ statistics are 2.58 for a $1 \%$ two-tailed test, 1.96 for $5 \%$ two-tailed test and 1.65 for a $10 \%$ two-tailed test. 
Table 7. Estimated Probability of Experiencing Technology Adoption Impediments

\begin{tabular}{|c|c|c|c|c|c|}
\hline & $\begin{array}{l}\text { Cost- } \\
\text { related } \\
(1)\end{array}$ & $\begin{array}{l}\text { Institution- } \\
\text { related } \\
\text { (2) }\end{array}$ & $\begin{array}{l}\text { Labour- } \\
\text { related } \\
\text { (3) }\end{array}$ & $\begin{array}{l}\text { Organization- } \\
\text { related } \\
(4) \\
\end{array}$ & $\begin{array}{c}\text { Information- } \\
\text { related } \\
(5)\end{array}$ \\
\hline & \multicolumn{5}{|c|}{ Percent } \\
\hline \multicolumn{6}{|l|}{ Number of tech use: } \\
\hline 0 & 66.1 & 14.4 & 21.1 & 17.8 & 12.7 \\
\hline $1-4$ & 78.6 & 14.4 & 21.1 & 17.8 & 12.7 \\
\hline $5-9$ & 77.4 & 14.4 & 21.1 & 17.8 & 21.4 \\
\hline $10+$ & 88.5 & 29.5 & 35.5 & 17.8 & 20.5 \\
\hline Innovator & 71.7 & 17.5 & 21.5 & 17.8 & 19.1 \\
\hline Non-innovator & 71.7 & 13.3 & 21.5 & 17.8 & 11.0 \\
\hline \multicolumn{6}{|l|}{ Region: } \\
\hline Atlantic & 61.1 & 7.4 & 17.7 & 10.2 & 12.9 \\
\hline Quebec & 69.2 & 8.8 & 14.2 & 18.3 & 12.9 \\
\hline Ontario & 73.7 & 22.0 & 26.4 & 18.3 & 12.9 \\
\hline Prairie & 73.7 & 13.9 & 26.4 & 18.3 & 18.9 \\
\hline British Columbia & 73.7 & 22.0 & 26.4 & 18.3 & 12.9 \\
\hline \multicolumn{6}{|l|}{ Industrial sector: } \\
\hline Core innovative & 71.7 & 11.5 & 21.5 & 19.1 & 13.7 \\
\hline Secondary innovative & 71.7 & 15.5 & 21.5 & 15.3 & 13.7 \\
\hline Other & 71.7 & 15.5 & 21.5 & 19.1 & 13.7 \\
\hline \multicolumn{6}{|l|}{ Number of competitors: } \\
\hline $0-5$ & 65.0 & 13.2 & 18.5 & 16.2 & 10.5 \\
\hline $6-19$ & 73.1 & 19.0 & 18.5 & 16.2 & 14.9 \\
\hline $20+$ & 75.0 & 13.2 & 26.2 & 20.5 & 15.3 \\
\hline \multicolumn{6}{|l|}{ Year of birth: } \\
\hline Before 1975 & 63.5 & 12.1 & 16.1 & 16.6 & 11.4 \\
\hline 1975-1984 & 70.7 & 12.1 & 21.4 & 21.1 & 11.4 \\
\hline After 1984 & 77.4 & 19.2 & 26.0 & 16.6 & 17.6 \\
\hline \multicolumn{6}{|l|}{ Output growth patterns: } \\
\hline Low & 71.7 & 13.3 & 18.1 & 17.8 & 13.7 \\
\hline Medium & 71.7 & 17.1 & 23.7 & 17.8 & 13.7 \\
\hline High & 71.7 & 13.3 & 23.8 & 17.8 & 13.7 \\
\hline Canadian-owned & 71.7 & 14.8 & 21.5 & 17.8 & 14.2 \\
\hline Foreign-owned & 71.7 & 14.8 & 21.5 & 17.8 & 10.2 \\
\hline \multicolumn{6}{|l|}{ Number of employees: } \\
\hline $1-19$ & 70.2 & 17.0 & 20.7 & 16.9 & 13.7 \\
\hline $20-99$ & 70.2 & 12.0 & 20.7 & 16.9 & 13.7 \\
\hline $100-499$ & 81.4 & 17.0 & 27.8 & 26.3 & 13.7 \\
\hline $500+$ & 70.2 & 4.9 & 20.7 & 16.9 & 13.7 \\
\hline Union & 71.7 & 14.8 & 24.1 & 21.1 & 13.7 \\
\hline Non-union & 71.7 & 14.8 & 20.5 & 16.6 & 13.7 \\
\hline
\end{tabular}


In short, while there is a common set of factors that significantly affect the likelihood of a firm reporting impediments, there are important differences. Cost-related problems are positively associated primarily with the intensity of technology use, the intensity of competition, and younger firms. Institution-related problems are more common among innovators and younger establishments. Regional differences associated with the actual probability of reporting an impediment are also quite striking in institution-related problems. Labour-related problems are more serious among firms that extensively use advanced technology, that face more intensive competition, in younger establishments, and in those experiencing higher growth. Organizationrelated problems are more characteristic of older, big and unionized establishments. Informationrelated problems are more typical among technology users; among innovators; among young firms; and among Canadian-owned establishments.

\section{Conclusion}

This paper has investigated various problems that firms in the Canadian manufacturing sector face as they adopt advanced technology. Although extremely important, the use of advanced technology is not widespread among manufacturing plants. One explanation lies in the fact that while advanced technologies provide a wide range of benefits, plants also face a series of impediments that prevent them from adopting advanced technology. There are broadly five categories of problems faced by firms-cost-related, institution-related, labour-related, organization-related, and information-related.

Cost-related problems include cost of capital, cost of technology acquisition, cost of related equipment acquisition, cost of related software development, and increased maintenance expenses. Institutional-related problems stem from taxation practices involving R\&D investment, tax credits and capital cost allowances, and from government regulations and standards. Labourrelated problems arise from a shortage of skills, training difficulties, and labour contracts. Organization-related problems are associated with difficulties in introducing changes to a firm's structure that are required for ingesting new technologies, poor management attitude, and worker resistance. Information-related problems arise from lack of scientific and technical information, technological services, and technical support from vendors.

With rare exceptions, it is observed that the percentage of plants reporting impediments is markedly and consistently higher among technology users than non-users; more frequent among innovating firms than those not introducing innovation. This suggests that impediments arise during the innovation process as firms learn by doing. Users in the process of adopting new technologies are confronted with various problems and must overcome them. Non-users may have a general idea of the importance of the various impediments, but until they face them they are unable to appreciate their severity. Some of these problems are very complex in nature, and their magnitudes cannot be easily determined ex ante.

Regression analysis confirms that many of the impediments are related to variables that capture the technological complexity of the firms-either incidence or intensity of technology use and innovator competencies. But these impediments are also positively associated with many plant 
characteristics that are correlated with technological competencies. Both of these facts substantiate the view that impediments are learned. They may be barriers; but they are barriers that do not stop innovation and the adoption of new technologies. They are obstacles that are overcome as technology is introduced into the plant. This confirms associated work that examined the differences between innovative and non-innovative firms in the service sector (Gellatly and Peters, 1999).

This view influences the way in which impediments outlined in technology and innovation surveys should be interpreted. They should not be interpreted as impenetrable barriers that prevent technological adoption. No doubt, such problems exist—but they are not what are being measured in these surveys. Rather these surveys indicated the area where successful firms face and solve problems. As such, they provide a guide as to the areas where those problems are likely to be more intense- though we must be cautious here with our interpretation because we do not have dollar measures; we only have the frequency of impediments that are reported.

It is also noteworthy that the nature of problems that have to be addressed differs across the various actors involved. Cost-related problems are higher where there is more competition and younger establishments. Institution-related problems are more common among innovators and younger establishments. Labour-related problems are more serious among firms that extensively use advanced technology, that face more intensive competition, younger establishments, and those experiencing higher growth. Organization-related problems are more likely in older, medium-sized and unionized establishments. Information-related problems are more typical among technology users; among innovators; among young firms; and among Canadian-owned establishments. Regional differences are also observed in all of these groups of impediments. Plants in the more technologically advanced regions face more impediments. 


\section{Appendix}

Table A1. Logistic Regression Results for Reporting Technology Adoption Impediments (Use of technology or not)

\begin{tabular}{|c|c|c|c|c|c|c|c|c|c|c|}
\hline \multirow[t]{2}{*}{$\overline{\text { Indep. Var. }}$} & \multicolumn{2}{|c|}{$\begin{array}{c}\text { Dep. Var. = Costprob } \\
\text { (1) }\end{array}$} & \multicolumn{2}{|c|}{$\begin{array}{c}\text { Dep. Var. = Instprob } \\
\text { (2) }\end{array}$} & \multicolumn{2}{|c|}{$\begin{array}{c}\text { Dep. Var. = Laboprob } \\
\text { (3) }\end{array}$} & \multicolumn{2}{|c|}{$\begin{array}{c}\text { Dep. Var. = Orgaprob } \\
\text { (4) }\end{array}$} & \multicolumn{2}{|c|}{$\begin{array}{c}\text { Dep. Var. = Infoprob } \\
\text { (5) }\end{array}$} \\
\hline & Coefficient & T-ratio & Coefficient & T-ratio & Coefficient & T-ratio & Coefficient & T-ratio & Coefficient & T-ratio \\
\hline User & 0.6467 & 5.33 & -0.0581 & -0.40 & 0.2110 & 1.78 & 0.2193 & 1.68 & 0.2325 & 1.59 \\
\hline Innovator & 0.1604 & 1.35 & 0.3620 & 2.49 & 0.1700 & 1.43 & 0.0871 & 0.66 & 0.6778 & 4.64 \\
\hline Atlantic & -0.5789 & -2.50 & -1.2743 & -3.19 & -0.5129 & -1.97 & -0.6863 & -2.10 & 0.3170 & 1.06 \\
\hline Quebec & -0.2230 & -1.78 & -1.0575 & -6.27 & -0.7666 & -5.69 & -0.1231 & -0.87 & 0.0879 & 0.54 \\
\hline Prairie & 0.1417 & 0.89 & -0.5549 & -2.87 & -0.0786 & -0.51 & 0.0882 & 0.52 & 0.4510 & 2.44 \\
\hline British Columbia & 0.0100 & 0.05 & -0.2393 & -1.08 & 0.0770 & 0.41 & -0.3582 & -1.55 & -0.1802 & -0.69 \\
\hline Core sector & 0.0154 & 0.10 & -0.2974 & -1.48 & 0.1368 & 0.88 & -0.1491 & -0.87 & 0.2994 & 1.65 \\
\hline Secondary sector & -0.1761 & -1.52 & -0.0606 & -0.42 & 0.1130 & 0.95 & -0.2637 & -1.96 & 0.0280 & 0.19 \\
\hline 6-19 competitors & 0.3869 & 2.95 & 0.4232 & 2.50 & 0.2321 & 1.65 & 0.1625 & 1.05 & 0.3644 & 2.10 \\
\hline $20+$ competitors & 0.4847 & 3.90 & 0.1775 & 1.08 & 0.4525 & 3.41 & 0.2910 & 1.99 & 0.4217 & 2.52 \\
\hline Born 1975-1984 & 0.3312 & 2.35 & -0.0393 & -0.20 & 0.3523 & 2.31 & 0.2935 & 1.82 & -0.0623 & -0.33 \\
\hline Born after 1984 & 0.6821 & 4.93 & 0.5509 & 3.10 & 0.6087 & 4.12 & 0.1740 & 1.09 & 0.5178 & 2.96 \\
\hline Medium growth & 0.0131 & 0.11 & 0.2993 & 2.07 & 0.3358 & 2.75 & 0.0654 & 0.48 & -0.0927 & -0.62 \\
\hline High growth & -0.2622 & -1.49 & 0.0700 & 0.31 & 0.3439 & 1.96 & 0.1721 & 0.93 & 0.1364 & 0.65 \\
\hline Canadian-owned & 0.2564 & 1.42 & -0.0327 & -0.15 & 0.1038 & 0.59 & -0.1558 & -0.85 & 0.3461 & 1.58 \\
\hline 20-99 employees & -0.1083 & -0.82 & -0.4148 & -2.48 & -0.0669 & -0.49 & 0.1289 & 0.85 & -0.0673 & -0.40 \\
\hline 100-499 employees & 0.6353 & 2.61 & -0.3596 & -1.23 & 0.4199 & 1.85 & 0.5744 & 2.39 & 0.1421 & 0.52 \\
\hline 500+ employees & 0.9132 & 1.76 & -0.7438 & -1.21 & 0.6348 & 1.50 & 0.6824 & 1.57 & 0.0398 & 0.08 \\
\hline Union & 0.1003 & 0.80 & 0.1915 & 1.23 & 0.2067 & 1.63 & 0.2960 & 2.18 & 0.1299 & 0.84 \\
\hline Constant & -0.3161 & -1.29 & -1.6838 & -5.42 & -1.9092 & -7.49 & -1.7714 & -6.60 & -3.0645 & -9.59 \\
\hline
\end{tabular}

Summary statistics:

\begin{tabular}{lccccc} 
S & 1936 & 1936 & 1936 & 1936 & \\
$\mathrm{n}$ (Dep. Var. =1) & 1326 & 318 & 558 & 406 & 309 \\
LL function & -1149.2 & -819.4 & -1108.1 & -961.7 & -813.7 \\
$\chi^{2}$ & 114.6 & 91.4 & 109.2 & 64.0 & 73.7 \\
$\%$ right prediction & 70.3 & 83.6 & 71.0 & 79.0 & 84.0 \\
\hline
\end{tabular}

Note: The reference groups are non-users, performing no innovative activities, located in Ontario, belonging to the "other" industrial sector, facing 0-5 competitors, born prior to 1975, experiencing low output growth, owned by foreigners, with 1-19 employees, and employees are not unionized. 
Table A2. Logistic Regression Results for Reporting Technology Adoption Impediments (Total number of technologies used)

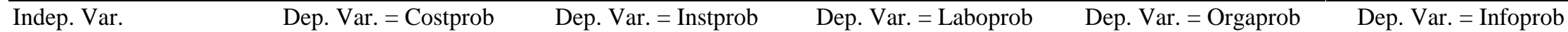

\begin{tabular}{|c|c|c|c|c|c|c|c|c|c|c|}
\hline & \multicolumn{2}{|c|}{ (1) } & \multicolumn{2}{|l|}{ (2) } & \multicolumn{2}{|c|}{ (3) } & \multicolumn{2}{|c|}{ (4) } & \multicolumn{2}{|l|}{ (5) } \\
\hline & Coefficient & T-ratio & Coefficient & T-ratio & Coefficient & T-ratio & Coefficient & T-ratio & Coefficient & T-ratio \\
\hline Tech use & 0.0991 & 3.95 & 0.0511 & 2.00 & 0.0574 & 2.74 & 0.0259 & 1.15 & 0.0569 & 2.37 \\
\hline Innovator & 0.1736 & 1.46 & 0.2899 & 1.98 & 0.1419 & 1.18 & 0.0981 & 0.74 & 0.6557 & 4.48 \\
\hline Atlantic & -0.5833 & -2.53 & -1.2500 & -3.13 & -0.5054 & -1.94 & -0.6899 & -2.11 & 0.3243 & 1.09 \\
\hline Quebec & -0.2543 & -2.04 & -1.0402 & -6.19 & -0.7712 & -5.73 & -0.1340 & -0.95 & 0.0849 & 0.53 \\
\hline Prairie & 0.1271 & 0.80 & -0.5431 & -2.81 & -0.0756 & -0.49 & 0.0849 & 0.50 & 0.4549 & 2.46 \\
\hline British Columbia & 0.0161 & 0.08 & -0.2048 & -0.92 & 0.0992 & 0.53 & -0.3541 & -1.53 & -0.1596 & -0.61 \\
\hline Core sector & 0.0485 & 0.31 & -0.3310 & -1.64 & 0.1273 & 0.81 & -0.1408 & -0.82 & 0.2952 & 1.62 \\
\hline Secondary sector & -0.1662 & -1.44 & -0.0665 & -0.46 & 0.1105 & 0.93 & -0.2606 & -1.94 & 0.0280 & 0.19 \\
\hline 6-19 competitors & 0.3915 & 2.99 & 0.4410 & 2.60 & 0.2420 & 1.72 & 0.1638 & 1.06 & 0.3745 & 2.16 \\
\hline $20+$ competitors & 0.4825 & 3.89 & 0.1799 & 1.09 & 0.4517 & 3.40 & 0.2914 & 1.99 & 0.4228 & 2.53 \\
\hline Born 1975-1984 & 0.3504 & 2.49 & -0.0547 & -0.28 & 0.3541 & 2.32 & 0.2986 & 1.86 & -0.0612 & -0.32 \\
\hline Born after 1984 & 0.6747 & 4.89 & 0.5364 & 3.02 & 0.6023 & 4.07 & 0.1727 & 1.09 & 0.5131 & 2.93 \\
\hline Medium growth & 0.0196 & 0.17 & 0.2899 & 2.01 & 0.3359 & 2.76 & 0.0693 & 0.51 & -0.0928 & -0.62 \\
\hline High growth & -0.2597 & -1.48 & 0.0501 & 0.22 & 0.3378 & 1.92 & 0.1720 & 0.93 & 0.1296 & 0.62 \\
\hline Canadian-owned & 0.2708 & 1.50 & -0.0016 & -0.01 & 0.1291 & 0.73 & -0.1511 & -0.82 & 0.3711 & 1.69 \\
\hline 20-99 employees & -0.0622 & -0.47 & -0.4563 & -2.74 & -0.0669 & -0.49 & 0.1503 & 1.00 & -0.0615 & -0.36 \\
\hline 100-499 employees & 0.6453 & 2.64 & -0.5222 & -1.76 & 0.3510 & 1.53 & 0.5915 & 2.44 & 0.0736 & 0.27 \\
\hline 500+ employees & 0.5816 & 1.08 & -1.1545 & -1.80 & 0.3359 & 0.75 & 0.6132 & 1.34 & -0.2496 & -0.47 \\
\hline Union & 0.1196 & 0.95 & 0.1757 & 1.13 & 0.2100 & 1.66 & 0.3063 & 2.27 & 0.1372 & 0.89 \\
\hline Constant & -0.2627 & -1.08 & -1.7393 & -5.60 & -1.9170 & -7.51 & -1.7468 & -6.53 & -3.0732 & -9.60 \\
\hline
\end{tabular}

\section{Summary statistics:}

$\mathrm{N}$

$$
\begin{aligned}
& \mathrm{n}(\text { Dep. Var. }=1) \\
& \text { LL function }
\end{aligned}
$$
$\chi^{2}$

1936
1326
-1155.4
102.3

$\begin{array}{cc}1936 & 1936 \\ 318 & 558 \\ -817.6 & -1106.0 \\ 95.2 & 113.5 \\ 83.6 & 71.7\end{array}$

$\begin{array}{cc}1936 & 1936 \\ 406 & 309 \\ -962.4 & -812.3 \\ 62.5 & 76.7 \\ 79.0 & 84.0\end{array}$

69.9

71.7

84.0

Note: The reference groups are non-users, performing no innovative activities, located in Ontario, belonging to the "other" industrial sector, facing $0-5$ competitors, born prior to 1975, experiencing low output growth, owned by foreigners, with 1-19 employees, and employees are not unionized. 
Table A3. Logistic Regression Results for Reporting Technology Adoption Impediments (Interaction between technology use and innovation)

\begin{tabular}{|c|c|c|c|c|c|c|c|c|c|c|}
\hline \multirow[t]{2}{*}{ Indep. Var. } & \multicolumn{2}{|c|}{$\begin{array}{c}\text { Dep. Var. = Costprob } \\
\text { (1) }\end{array}$} & \multicolumn{2}{|c|}{$\begin{array}{c}\text { Dep. Var. = Instprob } \\
(2)\end{array}$} & \multicolumn{2}{|c|}{$\begin{array}{c}\text { Dep. Var. = Laboprob } \\
\text { (3) }\end{array}$} & \multicolumn{2}{|c|}{$\begin{array}{c}\text { Dep. Var. = Orgaprob } \\
(4)\end{array}$} & \multicolumn{2}{|c|}{$\begin{array}{c}\text { Dep. Var. = Infoprob } \\
(5)\end{array}$} \\
\hline & Coefficient & T-ratio & Coefficient & T-ratio & Coefficient & T-ratio & Coefficient & T-ratio & Coefficient & T-ratio \\
\hline Non-user innovator & 0.1910 & 1.28 & 0.2556 & 1.35 & 0.3084 & 1.94 & 0.1190 & 0.66 & 0.6908 & 3.59 \\
\hline User innovator & 0.7936 & 4.99 & 0.3299 & 1.78 & 0.3543 & 2.30 & 0.3019 & 1.80 & 0.9094 & 4.88 \\
\hline User non-innovator & 0.6811 & 4.29 & -0.1794 & -0.89 & 0.3400 & 2.21 & 0.2478 & 1.45 & 0.2473 & 1.20 \\
\hline Atlantic & -0.5792 & -2.50 & -1.2748 & -3.19 & -0.5133 & -1.97 & -0.6865 & -2.10 & 0.3171 & 1.06 \\
\hline Quebec & -0.2204 & -1.76 & -1.0684 & -6.32 & -0.7552 & -5.59 & -0.1208 & -0.85 & 0.0891 & 0.55 \\
\hline Prairie & 0.1413 & 0.88 & -0.5542 & -2.87 & -0.0795 & -0.52 & 0.0878 & 0.51 & 0.4508 & 2.44 \\
\hline British Columbia & 0.0084 & 0.04 & -0.2278 & -1.02 & 0.0679 & 0.36 & -0.3604 & -1.56 & -0.1813 & -0.70 \\
\hline Core sector & 0.0161 & 0.10 & -0.2964 & -1.47 & 0.1378 & 0.88 & -0.1490 & -0.87 & 0.2993 & 1.65 \\
\hline Secondary sector & -0.1754 & -1.51 & -0.0620 & -0.43 & 0.1159 & 0.97 & -0.2635 & -1.96 & 0.0283 & 0.19 \\
\hline 6-19 competitors & 0.3882 & 2.96 & 0.4217 & 2.49 & 0.2367 & 1.68 & 0.1636 & 1.06 & 0.3650 & 2.10 \\
\hline $20+$ competitors & 0.4844 & 3.89 & 0.1819 & 1.10 & 0.4502 & 3.39 & 0.2906 & 1.99 & 0.4215 & 2.52 \\
\hline Born 1975-1984 & 0.3304 & 2.34 & -0.0400 & -0.21 & 0.3516 & 2.31 & 0.2930 & 1.82 & -0.0624 & -0.33 \\
\hline Born after 1984 & 0.6842 & 4.93 & 0.5412 & 3.04 & 0.6190 & 4.18 & 0.1763 & 1.11 & 0.5189 & 2.96 \\
\hline Medium growth & 0.0132 & 0.11 & 0.3003 & 2.08 & 0.3363 & 2.76 & 0.0659 & 0.48 & -0.0926 & -0.62 \\
\hline High growth & -0.2601 & -1.48 & 0.0642 & 0.28 & 0.3502 & 1.99 & 0.1738 & 0.93 & 0.1370 & 0.65 \\
\hline Canadian-owned & 0.2548 & 1.41 & -0.0298 & -0.14 & 0.1005 & 0.57 & -0.1565 & -0.85 & 0.3458 & 1.58 \\
\hline 20-99 employees & -0.1105 & -0.83 & -0.4095 & -2.44 & -0.0760 & -0.55 & 0.1266 & 0.84 & -0.0681 & -0.40 \\
\hline 100-499 employees & 0.6356 & 2.62 & -0.3674 & -1.25 & 0.4254 & 1.88 & 0.5748 & 2.39 & 0.1428 & 0.52 \\
\hline $500+$ employees & 0.9253 & 1.78 & -0.7846 & -1.27 & 0.6773 & 1.60 & 0.6906 & 1.59 & 0.0434 & 0.09 \\
\hline Union & 0.1015 & 0.80 & 0.1840 & 1.18 & 0.2128 & 1.68 & 0.2971 & 2.19 & 0.1303 & 0.84 \\
\hline Constant & -0.3239 & -1.32 & -1.6501 & -5.29 & -1.9528 & -7.59 & -1.7811 & -6.57 & -3.0695 & -9.49 \\
\hline \multicolumn{11}{|l|}{ Summary statistics: } \\
\hline $\mathrm{N}$ & 1936 & & 1936 & & 1936 & & 1936 & & 1936 & \\
\hline n (Dep. Var. $=1)$ & 1326 & & 318 & & 558 & & 406 & & 309 & \\
\hline LL function & -1149.2 & & -819.0 & & -1107.3 & & -961.7 & & -813.7 & \\
\hline$\chi^{2}$ & 114.8 & & 92.2 & & 110.9 & & 64.1 & & 73.8 & \\
\hline$\%$ right prediction & 70.4 & & 83.6 & & 71.4 & & 79.1 & & 84.0 & \\
\hline
\end{tabular}

Note: The reference groups are non-user non-innovator, located in Ontario, belonging to the "other" industrial sector, facing 0-5 competitors, born prior to 1975 , experiencing low output growth, owned by foreigners, with 1-19 employees, and employees are not unionized. 


\section{References}

Arundel, A. 1997. "Enterprise Strategies and Barriers to Innovation." In Innovation Measurement and Policies. Edited by A. Arundel and R. Garrelfs (eds.) European Commission, EIMS publication 50. pp. 101-108.

Australian Bureau of Statistics. 1989. Manufacturing Technology Statistics. Catalogue No. 81230. Canberra.

Baldwin, J.R. 1996. "Innovation: The Key to Success in Small Firms." In Evolutionary Economics and the New International Political Economy. Edited by J. de la Mothe and G. Paquette. London: Pinter.

Baldwin, J.R. 1999. Innovation, Training and Success. Research Paper No. 137. Analytical Studies Branch. Ottawa: Statistics Canada.

Baldwin, J.R. and M. Da Pont. 1996. Innovation in Canadian Manufacturing Enterprises. Catalogue 88-513-XPB. Analytical Studies Branch. Ottawa: Statistics Canada.

Baldwin, J.R. and B. Diverty. 1995. Advanced Technology Use in Canadian Manufacturing Establishments. Research Paper No. 85. Analytical Studies Branch. Ottawa: Statistics Canada.

Baldwin, J.R., B. Diverty and D. Sabourin. 1995. Technology Use and Industrial Transformation: Empirical Perspectives. Research Paper No. 75 Analytical Studies Branch. Ottawa: Statistics Canada. Also published in T. Courchene (ed.) Technology, Information and Public Policy. John Deutsch Institute for the Study of Economic Policy. Kingston, Ontario. Queen's University.

Baldwin, J.R., G. Gellatly, J. Johnson and V. Peters. 1998. Innovation in Dynamic Service Industries. Catalogue No. 88-516-XPB. Analytical Studies Branch. Ottawa: Statistics Canada.

Baldwin, J.R., T. Gray and J. Johnson. 1996. "Advanced Technology Use and Training in Canadian Manufacturing.” Canadian Business Economics 5: fall, 1996. 51-70.

Baldwin, J.R. and J. Johnson. 1996. "Business Strategies in Innovative and Non-Innovative Firms in Canada." Research Policy 25: 785-804.

Baldwin, J.R. and J. Johnson. 1998. "Innovator Typologies, Related Competencies, and Performance." In G. Eliasson, C. Green and C. McCann, Jr. (ed), Microfoundations of Economic Growth: A Schumpeterian Perspective, 227-253, Ann Arbor, Michigan: The University of Michigan Press.

Baldwin, J.R. and J. Johnson. 1999. "Innovation and Entry." In Are Small Firms Important? Their Role and Impact. Edited by Z. Acs. Kluwer. 
Baldwin, J.R. and P. Hanel. 2002. Knowledge Creation and Innovation Activity in an Open Economy. Cambridge: Cambridge University Press. Forthcoming.

Baldwin, J.R. and D. Sabourin. 1995. Technology Adoption in Canadian Manufacturing. Catalogue No. 88-512. Analytical Studies Branch. Ottawa: Statistics Canada.

Baldwin, J.R. and D. Sabourin. 1997. "Factors affecting technology adoption: A Comparison of Canada and the United States." Canadian Economic Observer. Ottawa: Statistics Canada. August pp. 3.1-3.17.

Baldwin, J.R., P. Hanel and D. Sabourin. 2001. "Determinants of Innovative Activity in Canadian Manufacturing Firms." In Innovation and Firm Performance. Econometric Explorations of Survey Data. Edited by Alfred Kleinknecht and P. Mohnen. London and Basingstoke: Palgrave. Forthcoming.

Baldwin, J.R., D. Sabourin and M. Rafiquzzaman. 1996. Benefits and Problems Associated with Technology Adoption in Canadian Manufacturing. Catalogue No. 88-514. Analytical Studies Branch. Ottawa: Statistics Canada.

Beaumont, N.B. and R.M. Schroder. 1997. "Technology, Manufacturing Performance and Business Performance amongst Australian Manufacturers.” Technovation 17(6) 297-307.

Cosh, A., A. Hughes and E. Wood. 1996. "Innovation in UK SMEs: Causes and the Consequences for Firm Failure and Acquisition." Working Paper 48. Cambridge: University of Cambridge ESRC Centre for Business Research.

Evangelista, R. and G. Sirilli. 1997. "Innovation in Services and Manufacturing: Results from the Italian Surveys." Working Paper 73. Cambridge: University of Cambridge ESRC Centre for Business Research.

Gellatly. G. and V. Peters. 1999. Differences in Innovator and Non-Innovator Profiles: Small Establishments in Business Services. Research Paper No. 143. Analytical Studies Branch. Ottawa: Statistics Canada.

OECD. 1991. Managing Manpower for Advanced Manufacturing Technology. Paris: Organisation for Economic Co-Operation and Development.

Papaconstantinou, G., N. Sakurai, A. Wyckoff, J. Fagerberg and E. Ionnidis. 1996. Technology Diffusion, Productivity and International Competitiveness: An Empirical Analysis. Report for the European Commission. EIMS Publication No. 13.

Rischel, T.D. and O.M. Burns. 1997. "The Impact of Technology on Small Manufacturing Firms." Journal of Small Business Management 35: 2-10. 
Robson, M., J. Townsend and K. Pavitt. 1988. "Sectoral Patterns of Production and Use of Innovations in the UK: 1945-1983." Research Policy 17: 1-14.

Small, M.H. 1998. "Objectives for Adopting Advanced Manufacturing Systems: Promise and Performance." Industrial Management and Data Systems 98: 129-37.

Spina, G., E. Bartezzaghi, A. Bart, R. Cagliano, D. Draaijer and H. Boer. 1996. Strategically Flexible Production: The Multifocused Manufacturing Paradigm." International Journal of Operations and Production Management 16: 20-41.

Tracey, M., M.A. Vonderrembse and J.S. Lim. 1999. "Manufacturing Technology and Strategy Formulation: Keys to Enhancing Competitiveness and Improving Performance." Journal of Operations Management 17: 4111-428.

United States Bureau of the Census. 1989. Manufacturing Technology 1988. SMT (88-1). Washington: U.S. Department of Commerce.

United States Bureau of the Census. 1993. Manufacturing Technology: Prevalence and Plans for Use: 1993. SMT (93-3). Current Industrial Reports. Washington: U.S. Department of Commerce.

Young, R.C., J.D. Francis and C. Young. 1993. "Innovation, High-Technology Use and Flexibility in Small Manufacturing Firms." Growth and Change 24: 67-86. 